\title{
Processing plants for food: Experimental grinding within the ERC-project PLANTCULT
}

\author{
Maria Bofill ${ }^{1}$, Danai Chondrou ${ }^{1}$, Antoni Palomo 1,2, Hara Procopiou ${ }^{3}$, Soultana \\ Maria Valamoti ${ }^{1}$
}

1. LIRA Laboratory, Department of Archaeology, School of History and Archaeology, Aristotle University of Thessaloniki, 54124 Thessaloniki, Greece \& Center for Interdisciplinary Research and Innovation

(CIRI-AUTH), Balkan Center, Buildings A \& B, 10th km Thessaloniki-Thermi Rd, P.O. Box 8318, 57001, Thessaloniki, Greece. Email: Bofill: marbof@hist.auth.gr; Chondrou: dachondr@hist.auth.gr; Valamoti:sval@hist.auth.gr;

2. Museu d’Arqueologia de Catalunya-Barcelona, Spain. Email: antoni.palomo@gencat.cat

3. Université Paris I - Panthéon-Sorbonne, Protohistoire Égéenne (UMR 7041ArScAn), France. Email: haris.procopiou@univ-paris1.fr

\begin{abstract}
:
PlantCult Project aims to explore the role of culinary traditions and innovations through their impact on shaping the social landscape in ancient Europe over long time periods (from the Neolithic period to the Iron Age) and large territories. The experimental program is part of an integrated study of food products and associated equipment focusing on whether the introduction of new species or changes in social and economic organization brought about changes in the food grinding technologies of the area.

The experiments include tools operated by back and forth reciprocal motion and circular motion, and manufactured from different raw materials, with different morphologies and sizes. The tools design and the list of plant ingredients (cereals, legumes, acorns and oil-seeds) ground in the experiments are all based on the archaeological record of the studied area (from the Aegean to Central Europe). In this paper we present the experimental protocol, the multi-scale methodology applied to the use-wear analysis (and the microbotanical sampling) of grinding stone tools, and the results of the experimental processing of the main plant ingredients detected in prehistoric European cuisine. Apprenticeship, productivity, the role of "big" and "small" tools and multifunctionality are some of the main issues tested experimentally in this study about grinding technologies.
\end{abstract}

Keywords: grinding stone tools; experimental archaeology; use-wear analysis; culinary practices; food identities; prehistoric Europe

\section{Introduction}

The PlantCult Project aims to achieve a new understanding of culinary practices in prehistoric Europe, through the integration of plant products (plant and food remains),

Published by the School of History, Classics and Archaeology, University of Edinburgh ISSN: 2055-0472. URL: http://journals.ed.ac.uk/lithicstudies/

Except where otherwise noted, this work is licensed under a CC BY 4.0 licence. 
associated equipment, such as grinding tools, written ancient sources and ethnography. Our interest in the role of culinary traditions and innovations refers to their impact on shaping the social landscape over long time periods (from the Neolithic period to the Iron Age) and large territories (e.g., between eastern and western Europe).

Culinary practices convert raw materials into edible food products and constitute a complex system of technical and cultural decisions that must be extensively analysed. The taste and the texture of food, crucial aspects in cuisine, are related to the processing techniques to which the ingredients are subjected along the food preparation process. From the pre-treatments of plant ingredients (drying, roasting, soaking, boiling, etc.) to the final cooking of the meal (baking, etc.), stone tools are the basic instruments used in the various stages to transform such ingredients.

Archaeological and ethnographic data suggest that the morphometric and raw material variation in grinding stone tools are related to technical and social implications that differ along different contexts. Among others, technical issues such as the access to raw materials, the technology of manufacturing and maintaining the tools, and social aspects such as the fineness of the desired ground product, are factors mediatized by the human societies. Through the multi-method analysis of intrinsic (raw material, morphology and size) and extrinsic (kinetics, productivity, use-wear traces, microbotanical residues, ground products) parameters of grinding stone tools, the PlantCult grinding experiments focus on how grinding activities are implicated in the food preparation of the main plant ingredients used in prehistoric Europe.

Plant food ingredients have changed over time in the project's study area, from the Aegean to Central Europe (focusing on modern Greece, Bulgaria, Austria, and Switzerland, see Valamoti et al. 2017: Fig.1). The plant ingredients of the Neolithic (glume wheats, barley, pulses, linseed and fruit) are enriched during the Bronze Age with additions that have origins in different places, following different trajectories as regards the timing of the introduction of each new species (Marinova \& Valamoti 2014; Stika \& Heiss 2013; Valamoti 2007). Through the project we are interested in exploring whether the introduction of new species or changes in social and economic organisation brought about changes in the food grinding technologies of the area. In order to do that we need to understand, among other things, the relationship between raw materials, tool shape, kinetics, output in terms of ground product, use-wear and associated plant micro-remains.

In this paper we present the experimental protocol, the multi-scale methodology applied to the surface characterization of grinding stone tools, and the results of the experimental processing of the main plant ingredients detected in prehistoric European cuisine.

\subsection{Grinding for food: a background of experimental grinding programs}

Experimentation in grinding technology was initially subscribed to the archaeological study of agricultural practices and the productivity of tool types (e.g. Foxhall 1982; MeurersBalke \& Lüning 1992). Subsequently, functional studies of grinding stone industries in specific study areas have carried out exhaustive manual experimental programs based on prehistoric sites in the Near East (Bofill 2015; Dubreuil 2002), China (Liu et al. 2010), Central Europe (Hamon 2006), Greece (Procopiou 1998; Valamoti et al. 2013) and the southwest of the Iberian Peninsula (Delgado 2008; Menasanch et al. 2002), among others (see references in Dubreuil et al. 2015: Tab. 7.2). Essential research questions guided most part of this experimental background, such as the effectiveness of grinding tools and the diagnostic use-wear patterns generated on grinding surfaces.

Intrinsic and external parameters of grinding tools such as raw material, size, morphology and kinetics have been unevenly treated in previous grinding experiments. Tool 
efficiency and degree of productivity are recurrently associated with raw material properties hardness, resistance to friction, abrasive capacity - as some researchers have analyzed (Delgado-Raack et al. 2009; Schneider 2002; Schoumacker 1993), as well as with the metrical attributes of tools - big Vs small artefacts - (Mildwaters \& Clarkson 2018). Tool size parameters have been partially analyzed in experimental projects on grinding technology, but many inferences concerning tool size and productivity or function of stone artifacts are often made in archaeological studies (e.g., Runnels 1981; Stroulia 2010; Stroulia et al. 2017; Tsoraki 2007, see also Valamoti et al. 2013 for further discussion on the topic).

Besides size, it is important to understand the way the tool was used (kinetics), in association with the morphological features of tools. PlantCult grinding experiments aim to provide a multifaceted approach that will allow a better understanding of how these different tool parameters affect the ground products and how they may have influenced the particular characteristics of the grinding stone assemblages recorded in prehistoric sites.

\subsection{Goals and limits of experimental grinding in PlantCult}

The experimental aspect of the project is closely interconnected to an overview to be obtained through the study of ancient tools, and pursues the following goals.

- To increase our knowledge about the grinding stone tool variation in prehistoric sites by connecting intrinsic tool parameters (raw material, morphology, size) with the operation of tools themselves, and the resulting use-wear patterns and ground products.

- To link grinding stone technology with variable culinary traditions and recipes, more than the nexus with one specific plant ingredient.

- To assess the social and technical dimensions of grinding stone technology in prehistoric societies.

Therefore, hypotheses on culinary techniques of plant processing during the prehistoric periods, which were previously based on macroscopic studies of the tools, will be tested and re-evaluated through the use-wear data, the experimental observations and the productivity results obtained in the experiments. Considering that the entire food preparation process depends on the final desired food product (e.g., nutritional contribution of ingredients, cultural meanings associated, taste and flavour, etc.), the experimental protocol includes several pretreatments (boiling, soaking, roasting, etc.) that affect the grinding stage, and the texture and taste of the final food product.

The concept of efficiency is often used in studies of archaeological tools as the amount of product that can be processed or the number of hours spent at completing a particular task. Efficiency is a relative concept: as long as a tool gets the job, it is efficient (Adams 2002:27). The design theory applied on grinding stones "focuses on the process of differential selection and modification of raw material in order to achieve a desired end product” (Adams 2010; Horsfall 1987: 333). Tool design (morphology, size, raw material, etc.) is also considered as more or less efficient in quantitative terms for grinding one or some grain species (Mildwaters \& Clarkson 2018), and allows to evaluate socio-economic asymmetries in prehistoric societies (Menasanch et al. 2002; Delgado \& Risch 2009).

During our experiments we tried to evaluate the links between tool design and the end product (for example: fine flour, coarse meal, etc.). In that sense, the time needed for each purpose and the user's perception of tiredness in each experimental sequence were recorded. The experimental protocol permits to observe how much time is needed to obtain $1 \mathrm{~kg}$ of the desired product, although in future steps we will use the unit of volume as many scholars do, inspired by ethnographic and textual evidence concerning units applied in pre-industrial societies (Foxhall 1982; Gregoire 1992). In order to follow use-wear formation on tools and to obtain worn surfaces comparable with the archaeological ones, experiments were 
conducted for longer periods (5h, 10h). Finally, the apprenticeship of the user was addressed through the execution of a secondary series of experiments in order to evaluate the impact of expertise on the grinding results.

\section{Materials and methods}

\subsection{Design of the experimental tools: Raw material, morphology, size and manufacture}

The focus is placed on tools operated by back-and-forth reciprocal motion and circular motion, and manufactured from different raw materials, morphologies and sizes (Figure 1). The raw material selection, the type of tools reproduced, and the list of plant ingredients processed, were all based on the archaeological record of the studied area (see Valamoti et al. in this volume).

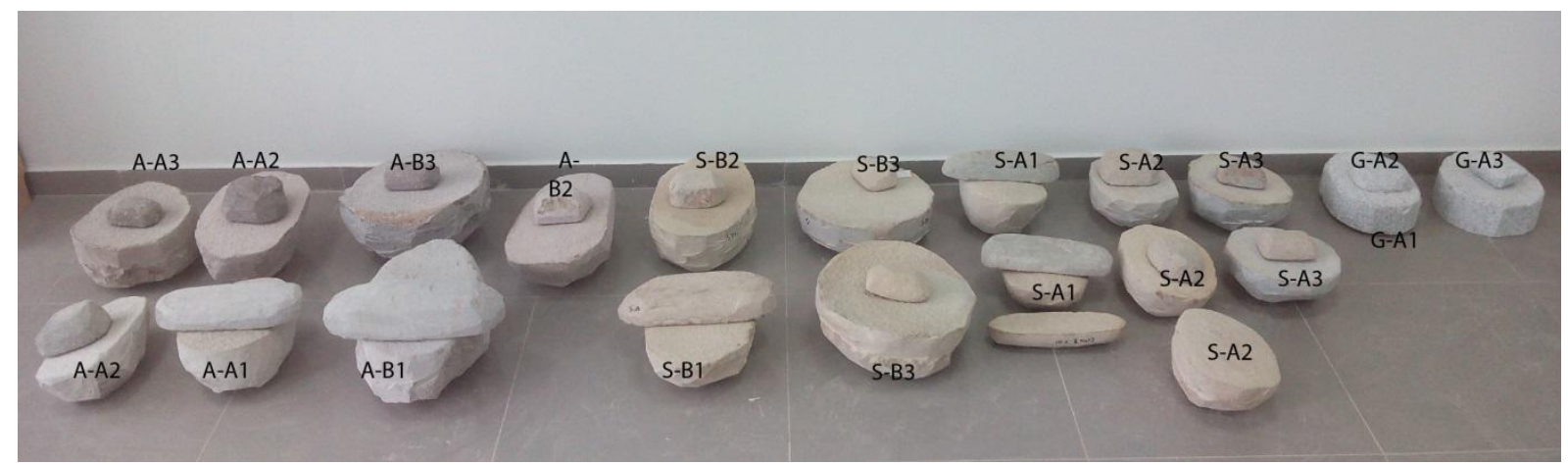

Figure 1. Experimental toolkits of different raw materials, sizes and morphologies.

Different rock types with different raw material properties that represent the main rock categories were selected from regional sources of Macedonia in northern Greece: sandstone, andesite and granite. The raw material procurement in collaboration with geologists (Geological Department - Aristotle University of Thessaloniki) was carried out in selected locations in that region (Figure 2a). Only granite was procured in a modern stone workshop due to limitations in the procurement of the stone. Petrographic analysis by means of thin section permitted to control raw material variability within the experimental tool database. The selected granite is the hardest material due to the high composition of quartz and good cohesion, followed by the non-porous andesite, and finally the sandstone. Sandstone can be characterized by a lower resistance to friction and a lower surface roughness (Delgado-Rack et al. 2009), which are key aspects for grinding purposes.

The experimental protocol included the manufacture of 6 tool pairs (quern and handstone) from each of the three raw materials (sandstone, andesite and granite), and five extra pairs of tools of the same types and size (in total: 40 artefacts). The experimental grinding tools fall into two major size categories, small (grinding slabs $<30 \mathrm{~cm}$ long) and big (>30 cm) implements, a conventional division that applies to the tendencies detected in the archaeological record (see measures in Table 1). Because of problems with the raw material procurement mentioned previously, only small size granite tools were replicated. 
a

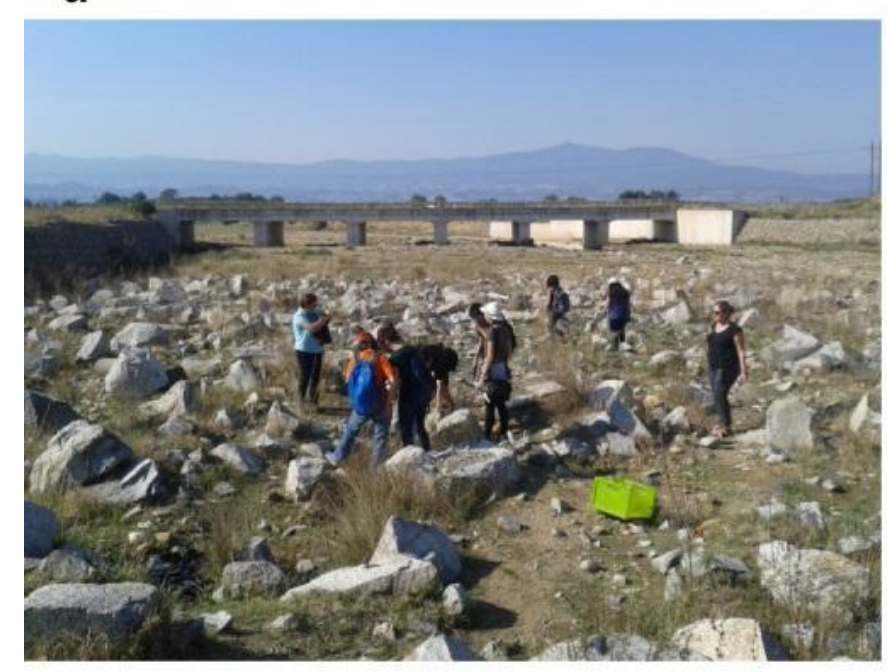

$d$

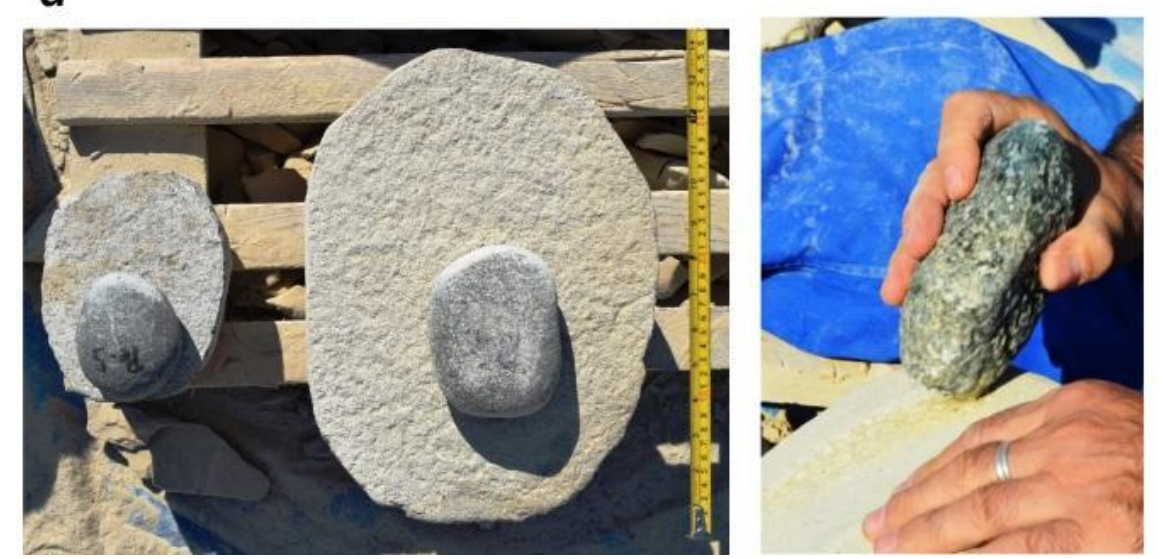

$b$

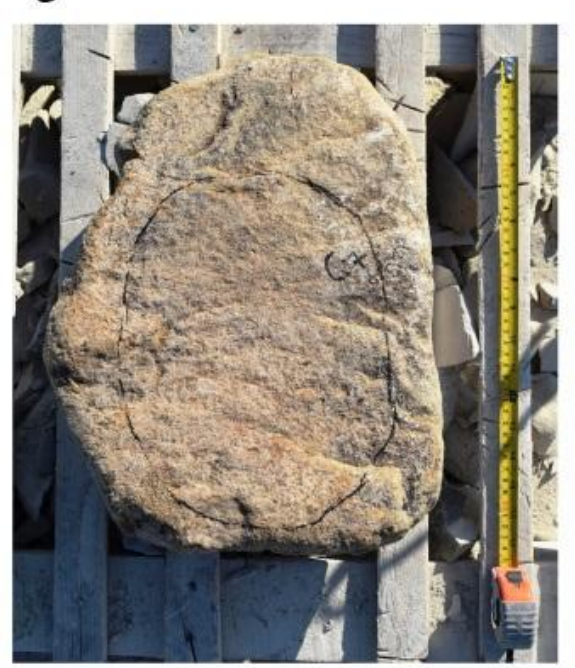

C
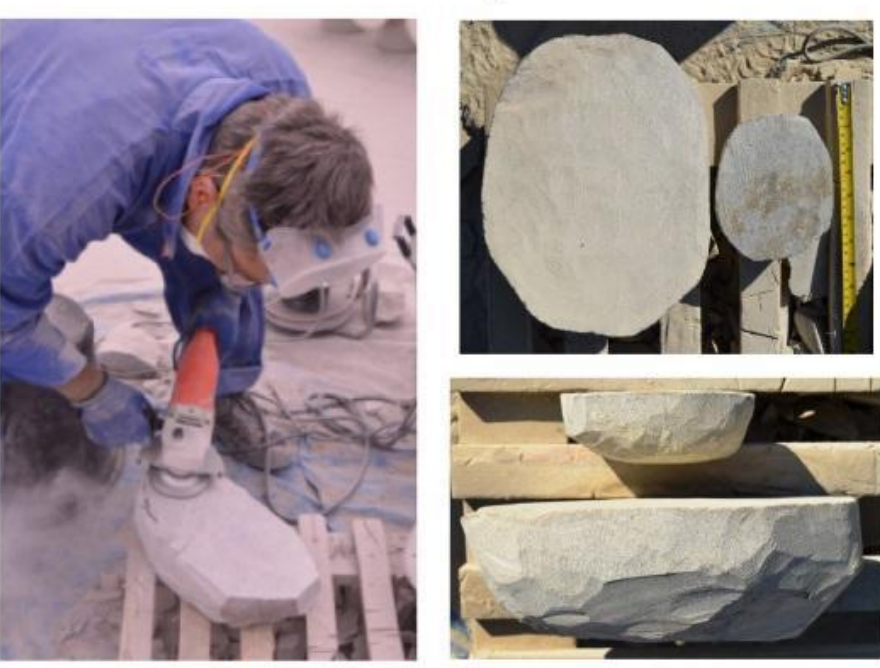

e

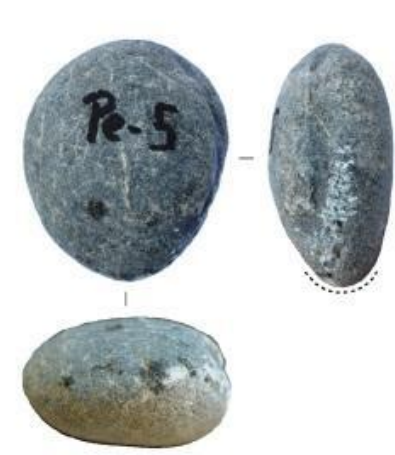

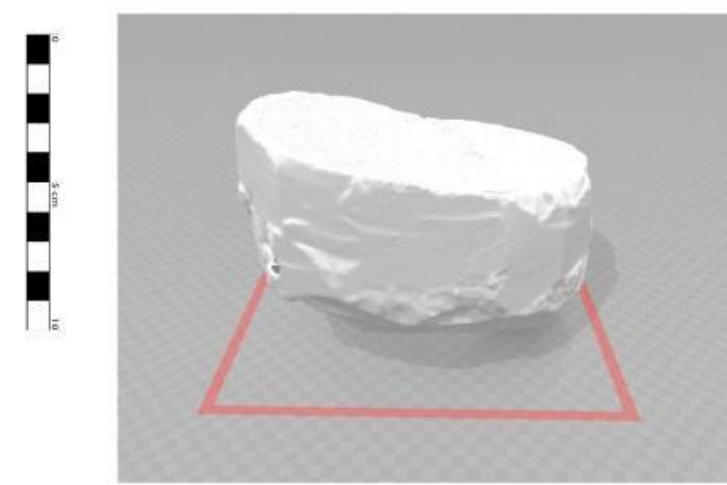

Figure 2. Raw material procurement in northern Greece area (a); manufacture process of the grinding stone tools using mechanical means to shape the boulders (b-c); and examples of hammerstones preparing the active surfaces by pecking (d). 3D scanning after the manufacture (e).

Journal of Lithic Studies (2020) vol. 7, nr. 3, 26 p. 
Three different categories were created based on the three basic tool-types of archaeological grinding implements that we come across: 1) grinding slab with handstone of the "overhanging" type used in a back and forth reciprocal motion 2) grinding slab with a small handstone used in a back and forth reciprocal motion 3) grinding slab with a small handstone used in a circular and free motion. These kinetics tend to create different morphologies (flat, convex, concave) of the grinding active surfaces that have been also manufactured for the experiments (Table 1). In the case of tool type 2, despite the flat morphology is the initial shape of these querns, their use in combination with the short handstone gradually creates a concave morphology of querns, which are very common in the archaeological record. This aspect was partially replicated in the experimental manufacture, creating a slight concavity ( $2 \mathrm{~mm}$ ) on querns of type 2 .

Table 1. Size, morphology and kinetics of PlantCult experimental grinding stone tool types. $q=$ quern; $h=$ handstone; $B \& F=$ Back and forth motion. Dimensions ${ }^{1}$ are given in $\mathrm{cm}$ for length (l.), width (w.) and thickness (t.), and in $\mathrm{kg}$ for weight (we.). Morphologies ${ }^{2}$ of the active surfaces are given as long axis section cross section.

\begin{tabular}{|c|c|c|c|c|c|c|}
\hline \multirow[b]{2}{*}{ Type } & \multicolumn{3}{|c|}{ A size tools (small) } & \multicolumn{3}{|l|}{ B size tools (big) } \\
\hline & Type A1 & Type A2 & Type A3 & Type B1 & Type B2 & Type B3 \\
\hline Dimensions $^{1}$ & $\begin{array}{l}\text { q. I.28; w.20; } \\
\text { t. } 7-10 ; \\
\text { we.11 } \\
\text { h. I. } 30 ; \text { w.14 } \\
\text { t.3-5; we.2,8 }\end{array}$ & $\begin{array}{l}\text { q. I.28; w.20; } \\
\text { t.9-12; we.11 } \\
\text { h. I.14; w.12; } \\
\text { t.3-5; we.1,2 }\end{array}$ & $\begin{array}{l}\text { q. I.28; } \\
\text { w.25; } \\
\text { t.:10-12; } \\
\text { we.12 } \\
\text { h.I.12; } \\
\text { w.9;t.5-6; } \\
\text { we.1,1 }\end{array}$ & $\begin{array}{l}\text { q. I.40; w. } 24 ; \\
\text { t.10-12; we.24 } \\
\text { h. I.36; w.16; } \\
\text { t.3-5; we.7 }\end{array}$ & $\begin{array}{l}\text { q. } 1.40 \text { w.24; } \\
\text { t.13-16; } \\
\text { we.22 } \\
\text { h. I.14; w.12; } \\
\text { t.3-5; we.1,9 }\end{array}$ & $\begin{array}{l}q .1 .40 \text { w.34 } \\
\text { t.16-19; } \\
\text { we.30 } \\
\text { h. I.14; w.12; } \\
\text { t.:3-5; } \\
\text { we.1,3 }\end{array}$ \\
\hline Morphology & q. PL-CX & $q . P L-P L$ & q. CV-CV & q. PL-CX & $q . P L-P L$ & q.CV-CV \\
\hline $\begin{array}{l}\text { of the active } \\
\text { surface }^{2}\end{array}$ & h. CV-CX & h.PL-PL & h. CX-CX & h. CV-CX & h.PL-PL & h. $\mathrm{CX}-\mathrm{CX}$ \\
\hline Kinetics & $\begin{array}{l}B \& F \\
\text { overhanging } \\
\text { handstone }\end{array}$ & $\begin{array}{l}B \& F \text { short } \\
\text { handstone }\end{array}$ & $\begin{array}{l}\text { Circular } \\
\text { and free } \\
\text { motion }\end{array}$ & $\begin{array}{l}B \& F \\
\text { overhanging } \\
\text { handstone }\end{array}$ & $\begin{array}{l}B \& F \text { short } \\
\text { handstone }\end{array}$ & $\begin{array}{l}\text { Circular and } \\
\text { free motion }\end{array}$ \\
\hline
\end{tabular}

At the first stage of the manufacture process mechanical means were used for accelerating the shaping process (Figures $2 b-c$ ), while special emphasis was later placed on the preparation of the active surfaces by using different hammerstones. Various technical gestures in the pecking process, combining different impact orientation and degrees of inclination were tested, depending on the surface to be pecked (Figure 2d). Gabbro, gneiss, quartz and amphibolite pebbles were used as hammerstones, as detected from the archaeological record. A representative group of experimental tools were 3D scanned in order to record morphological features and macro-traces generated during the manufacture process (Figure 2e). 
Table 2. List of plant ingredients used in the experiments.

\begin{tabular}{|c|c|c|c|}
\hline Experiment & Ingredient & State / pre-treatment & Processing \\
\hline E1 & Einkorn (T. monococcum) & Dehusked & Fine grinding \\
\hline E2.1 & Einkorn (T. monococcum) & Dehusked & Fine grinding \\
\hline $\mathrm{E} 2.1 \mathrm{~b}$ & Einkorn (T. monococcum) & Hulled (untreated) & Fine grinding \\
\hline E2.3 & Barley (Hordeum vulgare) & Hulled (untreated) & Fine grinding \\
\hline E2.4 & $\begin{array}{l}\text { Millet (Panicum } \\
\text { miliaceum) }\end{array}$ & Dehusked & Fine grinding \\
\hline$E 2.4 b$ & $\begin{array}{l}\text { Millet (Panicum } \\
\text { miliaceum) }\end{array}$ & Hulled (untreated) & Fine grinding \\
\hline E2.5 & Barley (Hordeum vulgare) & Malt, commercial & Coarse grinding \\
\hline E2.6 & Bitter vetch (Vicia ervilia) & Untreated & Splitting \\
\hline $\mathrm{E} 2.6 \mathrm{~b}$ & Bitter vetch (Vicia ervilia) & Split/sieved/winnowed & Fine grinding \\
\hline E2.7 & $\begin{array}{l}\text { Linseed (Linum } \\
\text { usitatissimum) }\end{array}$ & Untreated & Fine grinding \\
\hline$E 2.7 b$ & $\begin{array}{l}\text { Linseed (Linum } \\
\text { usitatissimum) }\end{array}$ & Roasted & Fine grinding \\
\hline E2.8 & Acorns (Quercus sp.) & Dried & Fine grinding \\
\hline $\mathrm{E} 2.8 \mathrm{~b}$ & Acorns (Quercus sp.) & Roasted & Fine grinding \\
\hline E2.9 & Lentils (Lens culinaris) & Untreated & Splitting \\
\hline $\mathrm{E} 2.9 \mathrm{~b}$ & Lentils (Lens culinaris) & Split/sieved/winnowed & Fine grinding \\
\hline E2.10 & $\begin{array}{l}\text { Poppy seeds (Papaver } \\
\text { somniferum) }\end{array}$ & Untreated & Fine grinding \\
\hline$E 2.10 b$ & $\begin{array}{l}\text { Poppy seeds (Papaver } \\
\text { somniferum) }\end{array}$ & Roasted & Fine grinding \\
\hline E2.11 & Spelt (T. spelta) & $\begin{array}{l}\text { Grünkern: Unripe and } \\
\text { smoked }\end{array}$ & Coarse Grinding \\
\hline E3.1 & Einkorn (T. monococcum) & De-husked & Fine grinding \\
\hline E3.2 & Einkorn(T. monococcum) & Hulled & Fine grinding \\
\hline E3.3 & Einkorn(T. monococcum) & De-husked & Coarse grinding \\
\hline E3.4 & $\begin{array}{l}\text { Grass Pea (Lathyrus } \\
\text { sativus) }\end{array}$ & Untreated & Splitting \\
\hline$E 3.4 b$ & $\begin{array}{l}\text { Grass Pea (Lathyrus } \\
\text { sativus) }\end{array}$ & Split/sieved/winnowed & Fine grinding \\
\hline E4 & $\begin{array}{l}\text { Barley (Hordeum } \\
\text { vulgare), millet (Panicum } \\
\text { miliaceum), Grass Pea } \\
\text { (Lathyrus sativus), acorns } \\
\text { (Quercus sp.) }\end{array}$ & $\begin{array}{l}\text { Hulled barley, de- } \\
\text { husked millet, } \\
\text { split/sieved/winnowed } \\
\text { grass pea, roasted } \\
\text { acorns }\end{array}$ & Fine grinding \\
\hline
\end{tabular}

\subsection{Plant ingredients: species and pre-treatments}

The plant species selected and the various treatments of the grains before their experimental grinding (Table 2) correspond to finds from the archaeobotanical record from the PlantCult study region where they have been found in rich concentrations or occurring regularly at different sites (Stika \& Heiss 2013; Valamoti 2009). Moreover, they correspond to finds that form the focus of the archaeobotanical study in the context of PlantCult, i.e., 
ground cereals, split pulses, bread, malt and Grünkern spelt (see Heiss et al. 2017; Valamoti 2011; Valamoti et al. 2013; 2017).

\subsection{Data recording, grinding sequences, cleaning procedure and sampling}

Every experimental sequence in Experiments 1 and 2 was developed during 5 h, divided in three stages: _a (60 min),_b (120 min) and _c (120 min). Sequences in Experiment 3 were $10 \mathrm{~h}$, and $8 \mathrm{~h}$ in Experiment 4 . The sequences were all performed by two grinders. With regards to the tool feeding, the users noted the time invested in processing every $200 \mathrm{~g}$ of grain in each experimental stage. At the end of each grinding sequence, the ground product was weighted, and the microbotanical sampling (for starch and phytolith analysis) was carried out, prior to the washing of the grinding tools and the use-wear analysis.

Regarding the grinders and tools position during the experiments, seating on the knees was selected for being the most widespread position according to ethnographic data and archaeological evidence for the Neolithic period. For the experiments, the grinding toolkit was placed in a wooden box filled with earth in order to get a correct inclination between the grinder's body (seated on the knees) and the quern (slightly raised with regard to the knees level). However, the standing position is also attested in the Late Bronze Age and in the classical period, and is the most adapted to our habits (to avoid tiredness). This body position would be included in future experiments.

After the microbotanical sampling, the cleaning procedure of the experimental surfaces included intensive cleaning with soapy water and a brush in order to remove all residues. The soap-\&-brush procedure was more efficient than the use of a sonicator bath used by other researchers in lithic technology, probably because of the presence of deeper interstices on the grinding surfaces. Current scholars working on macrolithic artefacts also found this washing procedure the most suitable (Dubreuil et al. 2015). Occasionally, when the brushing with warm soapy water did not eliminate oily remains (i.e., linseed and poppy seed), an additional cleaning with alcohol $96 \%$ was applied. Finally, after each sequence of Experiment 1, 2 and 3 , the active surfaces of the quern and the handstone were re-pecked in order to obtain a new surface and remove the preceding use-wear traces. No re-pecking was done during Experiment 4, since the aim of this experiment was to obtain a cumulative use-wear signature after the processing of different plant ingredients.

In parallel to the surface analysis, we conducted the analysis of the ground product obtained in each sequence, in order to check the attributes of the meals, like particle-size (degree of fineness), presence of other seeds, presence of grains envelops (husk), and also the presence of stone particles that contaminate the meals (Figure 3a-b). This part of the analysis (currently under study) is an essential step to fully understand the characteristics of the ground ingredients for the subsequent prehistoric recipes.

\subsection{Use-wear analysis of experimental tools}

Concerning the surface analysis of grinding tools, the use-wear approach is based on the macroscopic view and various scales of microscopic analysis of grinding surfaces (Adams 2002; Adams et al. 2009). The PlantCult project integrates different tribological methods and techniques into a new multi-scale functional study of grinding stone surfaces (Bofill 2015; Bofill et al. 2013; Procopiou et al.1998; Vargiolu 2008). 

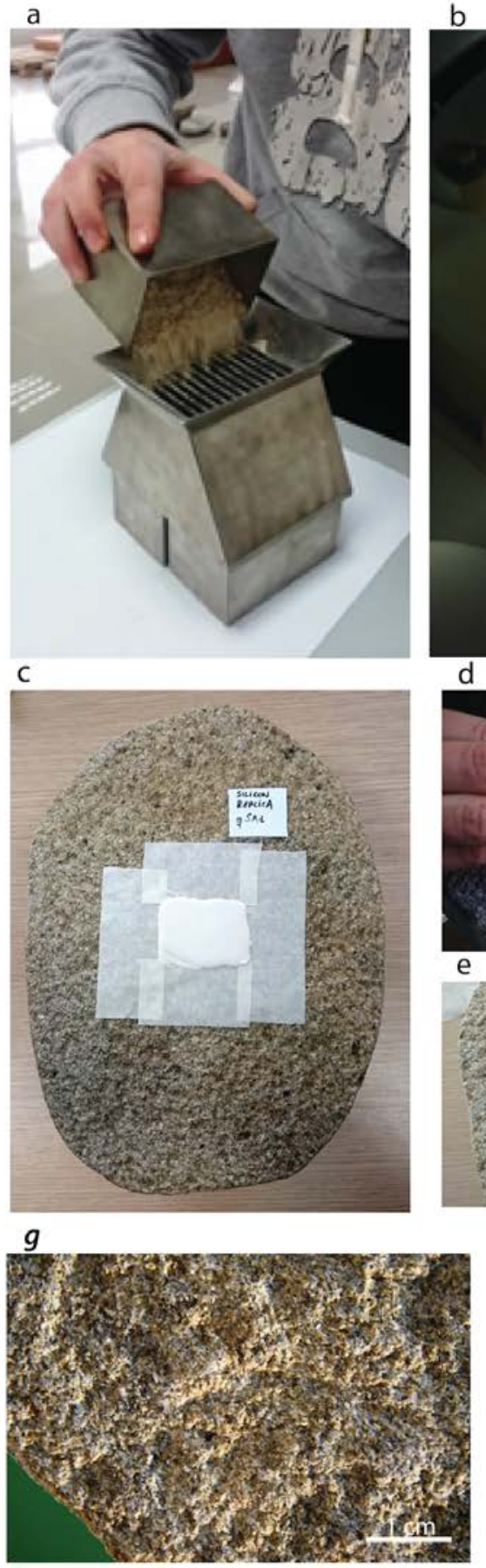

h

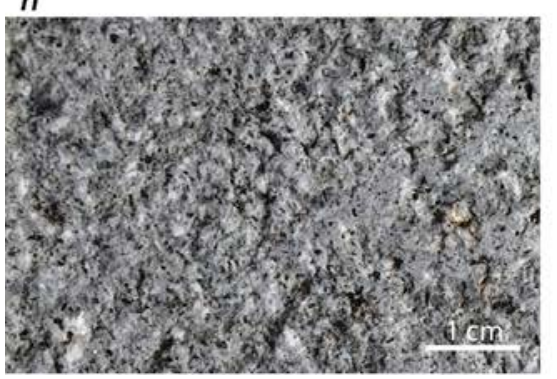

b
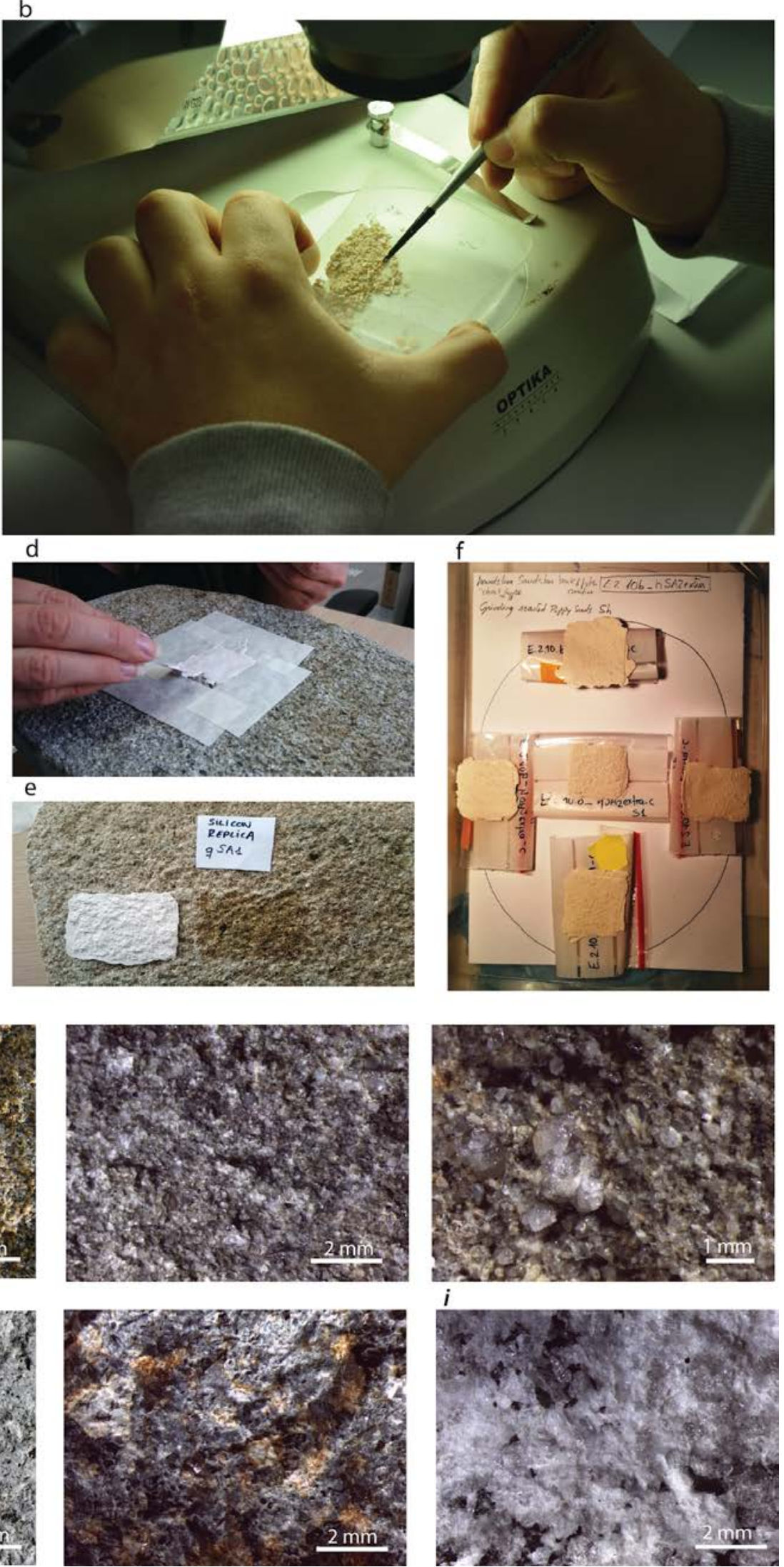

Figure 3. Images of the ground product analysis (a-b) and the tool surface sampling using Silflo® ${ }^{\circledR}$ casts (c-f). Pecked surfaces after the manufacture: sandstone (g), andesite (h) and granite (i). 
First of all, the macro-scale analysis of entire surfaces to identify the distribution of usewear patterns was recorded by using 3D scanning (2Corp Scanner 700LX), and macrophotography (Nikon D3300). Secondly, low power surface analysis by using a Leica M80 stereomicroscope ( $7.5 \mathrm{x}$ to $60 \mathrm{x})$ permitted to characterize use-wear traces associated with the grinding process (linear traces, levelled areas, microfractures, polish). About the illumination, the equipment included a double-armed gooseneck with two integrated LED spotlights (Leica LED 3000 SLI).

At the final stage, the high power analysis integrated metallographic microscopy (> 100x) with surface measurements and characterization with confocal microscopy (micro-scale analysis of surface samples), also supported by the use of resin casts over different areas of the experimental surfaces (Silflo®; Figure 3c-f). This part of the project has been carried out in collaboration with the Laboratoire of Tribology des Systèmes (Ècole Centrale de Lyon), and will be presented in further publications.

In this paper we will focus on two of the three scales of surface analysis: the macroscopic analysis and the low power analysis of surfaces by means of stereomicroscope.

\section{Experimental results}

\subsection{Manufacture process}

One of the most important goals of the manufacturing process was to achieve a perfect coupling between the quern and the handstone surfaces. This technical feature determined the quality of the ground product, as well as the tiredness of the person who used the tools (bad coupling $=$ more time and effort). This last aspect was observed in some tool pairs that after the first experimental sequences had to be restored by repecking in order to get the correct join between active surfaces (quern and handstone).

As it was expected considering the stone properties, granite was the most time consuming raw material in terms of manufacture effort, followed by andesite, and finally sandstone (Table 3). The roughness of the initial pecked surfaces was the basis of the usewear traces generated later on during the grinding experiments (Figures 3g-i).

Table 3. Timings in the manufacture of experimental querns. Because of problems with raw material procurement, big granite querns were not manufactured in the experiments*.

\begin{tabular}{|c|c|c|c|c|}
\hline \multirow{2}{*}{$\begin{array}{l}\text { Raw material } \\
\text { Sandstone }\end{array}$} & \multicolumn{4}{|c|}{ Timings of querns manufacture } \\
\hline & A-small & Type 1 & Type 2 & Type 3 \\
\hline & & $30 \mathrm{~min}$ & $35 \mathrm{~min}$ & $40 \min$ \\
\hline & B-big & Type 1 & Type 2 & Type 3 \\
\hline & & $45 \mathrm{~min}$ & $70 \mathrm{~min}$ & $55 \mathrm{~min}$ \\
\hline \multirow[t]{4}{*}{ Andesite } & A-small & Type 1 & Type 2 & Type 3 \\
\hline & & $35 \mathrm{~min}$ & $45 \mathrm{~min}$ & $60 \mathrm{~min}$ \\
\hline & B-big & Type 1 & Type 2 & Type 3 \\
\hline & & $90 \mathrm{~min}$ & $40 \mathrm{~min}$ & $85 \min$ \\
\hline \multirow[t]{2}{*}{ *Granite } & A-small & Type 1 & Type 2 & Type 3 \\
\hline & & $45 \mathrm{~min}$ & $50 \mathrm{~min}$ & $60 \mathrm{~min}$ \\
\hline
\end{tabular}

\subsection{Grinding experiments}

\subsubsection{Experiment 1: Multiple tools processing 1 species (dehusked einkorn)}

Experiment 1 was aimed at investigating how the raw material, the size, the morphology and the kinetics of grinding tools affect the processing of one specific plant ingredient (in this case, dehusked einkorn; Figure 4). Different tool sizes and different active surface 
morphologies (see Table 1 for codes) are combined using three raw materials (sandstone, granite and andesite). Figure 5a shows the results of small (A) and big (B) tools in the different rock types and tool types performed in Experiment 1. As the duration was stable among the different grinding sequences it is possible to identify differences among toolkits by means of the user impressions and the productivity results.
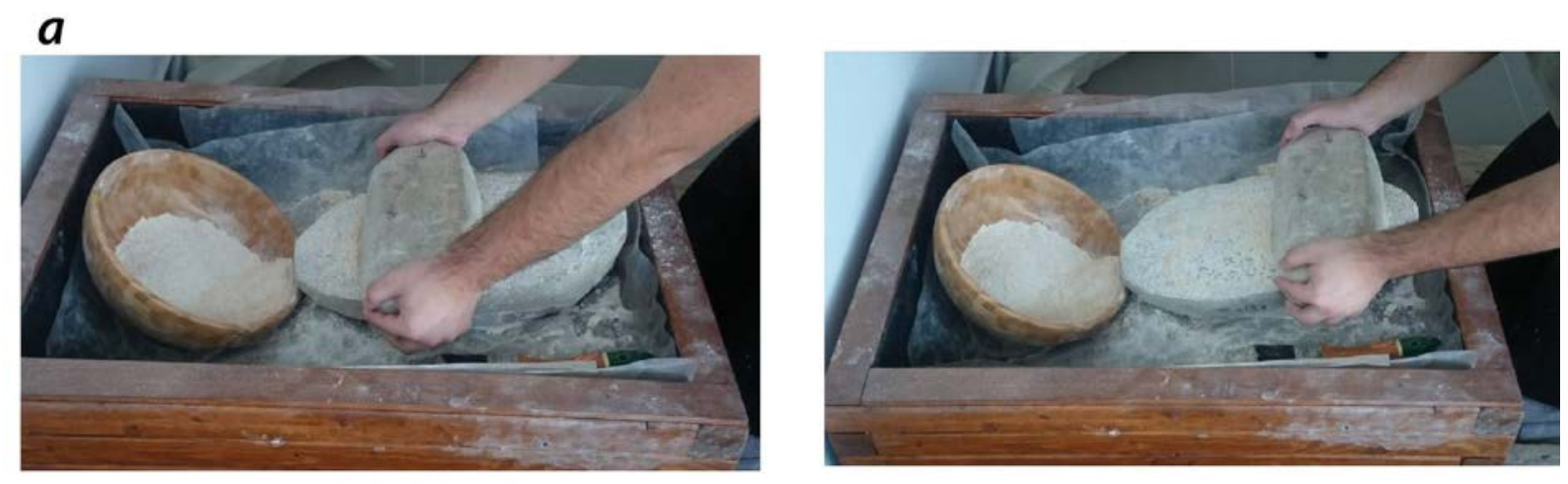

$b$
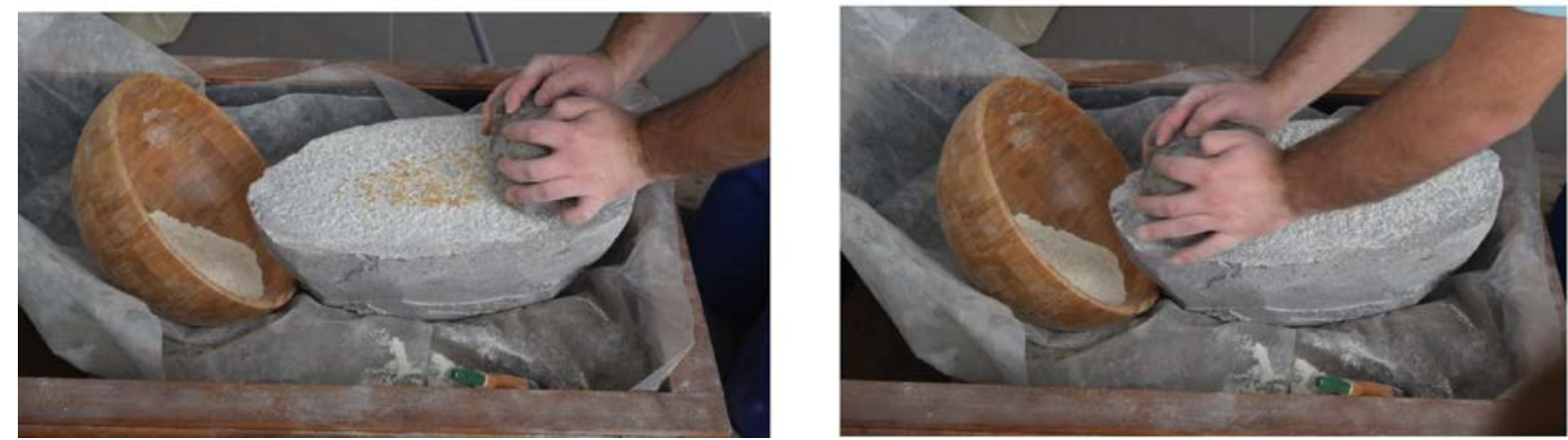

Figure 4. Experimental sequences. Experiment 1 grinding dehusked Einkorn with type 1 (a) and type 2 (b).

As a general trend, only granite tool type GA2 and andesite AA3 produced substantially higher quantities of the product compared to sandstone tools. As it will be shown in the next observations, type 3 tends to offer better results in terms of the quantity of the ground product. The trial with the granite toolkit GA2, performed with a back and forth motion and with a short handstone, achieved better results than other toolkits due to the hardness of the granite combined with the good coupling between the quern and handstone. Despite the differences among the results of the stones analyzed, sandstone still reached good results in terms of the quantity of the ground product, a fact that could explain the high percentage of this raw material among the grinding stone assemblages of the study areas.

Regarding morphology and kinetics, the experimental data on Experiment 1 suggest no clear differences between tool types in terms of quantity of product generated. Only type 3 showed higher results with some of the toolkits (andesite and sandstone). More significant is the experience of the two team grinders, both of whom consider type $\mathbf{3}$ as the easiest to handle, and type 1 as the most difficult to get used to. As M. Mauss (1950) and other anthropological studies (Geslin 1999; Sigaut 2003) showed, the perception “easy to handle” is also related to cultural and social factors. Next steps of the experimentation will explore the different types of tools processing different plant ingredients, and in different states of the meal (hulled or dehusked, boiled, roasted, etc.).

Each toolkit required a period of training for each of the team grinders, depending on the weight and the morphology of the handstone (ease of holding), and the type of motion that had to be reproduced. Due to this reason, a second series of the same Experiment 1 was 
carried out in order to check the impact of the learning process in the grinding sequences (the productivity test shown in Figure $5 \mathrm{~b}$ ). The results were conspicuously significant in increasing the quantity of product in the second replication of each grinding process.

Finally, the comparison of "big" tools to "small" tools (Figure 6) indicates the difference concerning the size variable, an important question related to the scale of production and the organization of grinding activities. Big tools produced an average of 1,090 kg per $120 \mathrm{~min}$, and small ones reached 0,667 $\mathrm{kg}$ per $120 \mathrm{~min}$.
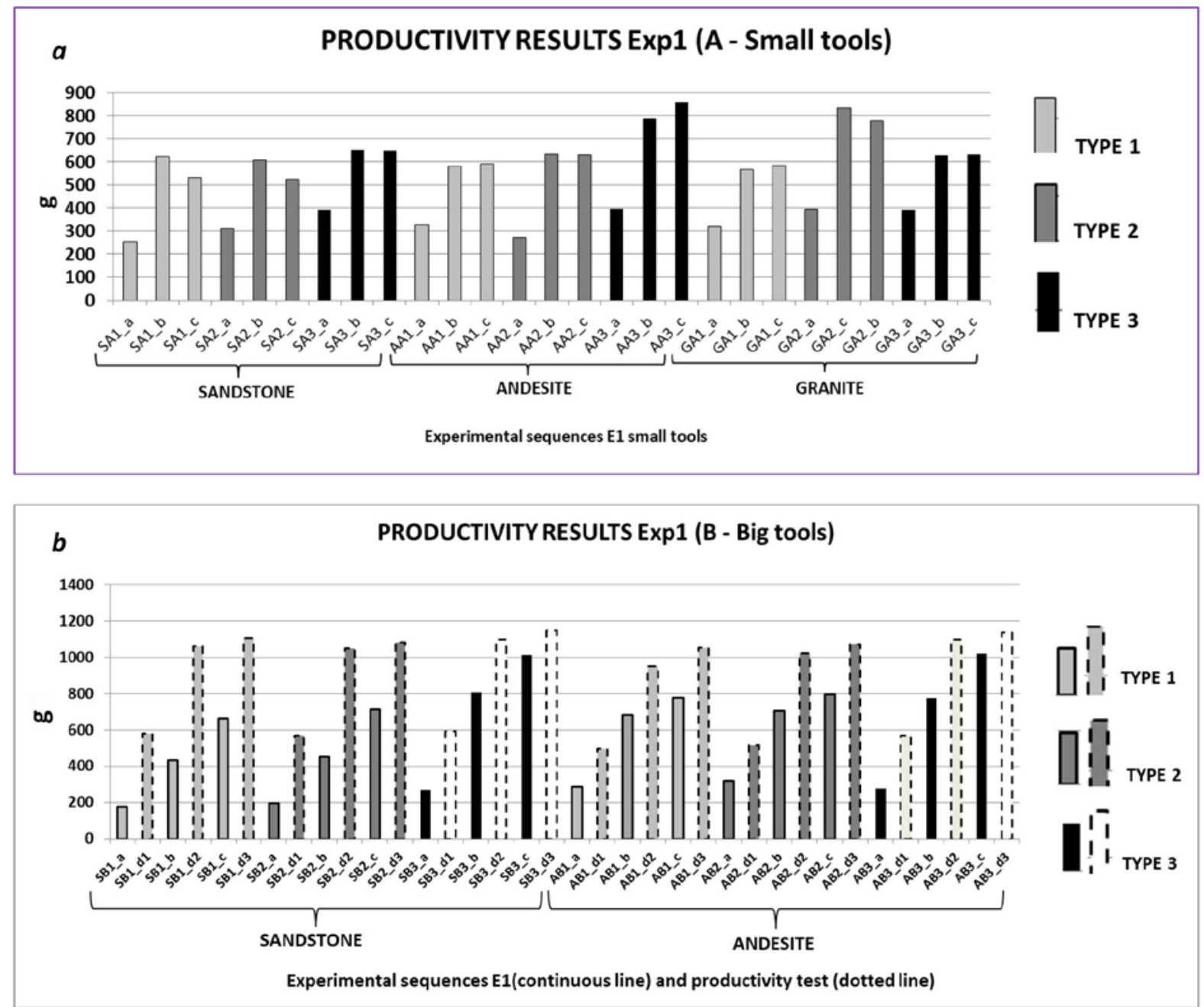

Figure 5. Results of Experiment 1 - small tools (a, above) and big tools (b, below). The dotted lines indicate the sequences done in the productivity test. Times in all experimental sequences are stable: _a= 60 min; _b=120 min;_c =120 min;_d1=60min; d2_120 min;_d3 = 120 min. Codes of grinding tools are in Table 1 .

\subsubsection{Experiment 2: Single tool processing multiple species}

The second experiment is focused on the role of the material processed in the use-wear formation, and on how the most common tool type can process different plant ingredients. For this reason the use of the same pair of tools was maintained constant during the experiment, and the grinding of different plant ingredients was reproduced separately. We chose sandstone A2, since it represents one of the most frequently encountered implement types in the archaeological record.

Most of the experimental sequences in Experiment 2 show good results in terms of viability of using SA2 toolkit with different plant ingredients and types of ground product. 
Despite this general trend, several issues must be discussed to understand the multi-functional or specialized character of archaeological grinding tools:

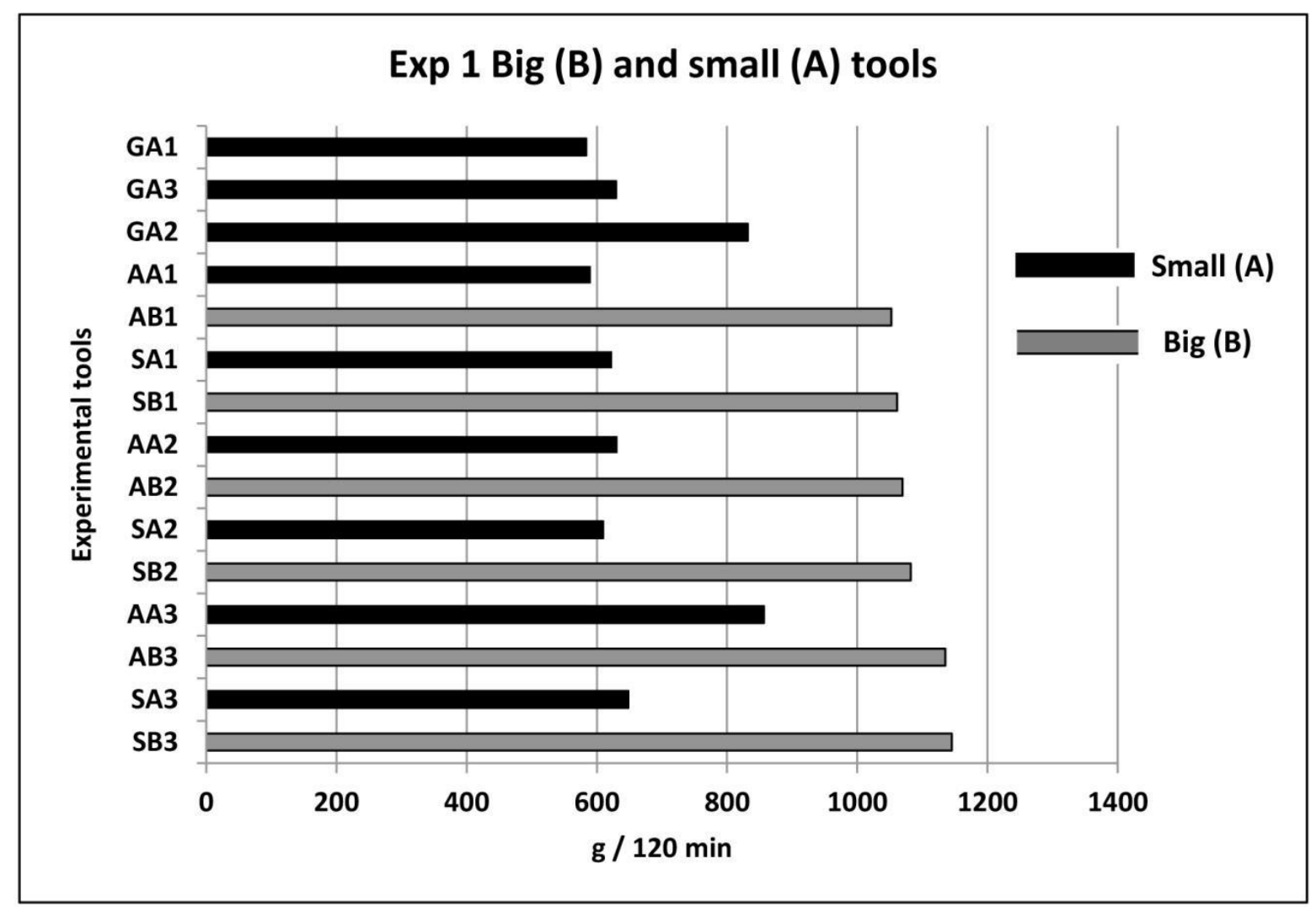

Figure 6. Experimental highest results of A tools (small) and B tools (big) in sequences of 120 min. Codes of grinding tools are in Table 1: $\mathrm{A}=$ andesite, $\mathrm{S}=$ sandstone, $\mathrm{G}=$ granite.

- Hulled and dehusked cereals. The processing of hulled cereals implied more hand pressure effort and time than the processing of clean and dehusked grains (personal observation of the grinders), especially in the case of barley. Such difficulty decreases the productivity of processing hulled cereals. Among the different cereal species, dehusked millet (Figure 7) processing reached the highest flour productivity in Experiment $2(0,957 \mathrm{~kg}$ per $120 \mathrm{~min}$ ). A second experimental replication of this sequence (Figure 8) was done by changing the raw material and the type of grinding tool used: andesite type 3 (AA3), was a combination that reached a higher productivity $(1,300 \mathrm{~kg}$ per $120 \mathrm{~min})$ than the previous sequence with SA2 tools.

- Coarse grinding. Compared to fine grinding (Figure 9a), coarse grinding produces cereal groats (i.e., for malt processing, bulgur, Grünkern) more easily. The user does not need to exert as much strength in the processing; therefore in a few strokes the groats are produced (Figure 9b). The grinding process is fast, reaching good results in terms of productivity (circa $0,800 \mathrm{~kg}$ per $120 \mathrm{~min})$. However, with this manual technique it is almost impossible to control the particle-size obtained. Subsequently, a secondary process of sieving and/or winnowing will be needed to separate the desirable particle-size of the ground product depending on the type of dish.

- Acorn processing. Different pre-treatments such as drying and roasting were experimentally performed in order to check how they affect the de-shelling (to separate the outer shell) and the subsequent grinding process. According to ethnographic data, roasting was one of the methods applied for the removal of bitter tannins, or to facilitate the removal 
of the shell or the testa, either for acorns to be eaten whole or prior to their grinding (Driver 1952; Mason \& Nesbitt 2009; Vlencl 1996). The user noticed that it was easier to de-shell the roasted acorns than the dried ones. However, the roasted acorns were harder to grind compared to the dried ones, an observation that was not well reflected in the quantitative results (roasted maximum 0,433 kg per $120 \mathrm{~min}$; dried maximum 0,489 kg per $120 \mathrm{~min}$; Figure 10).

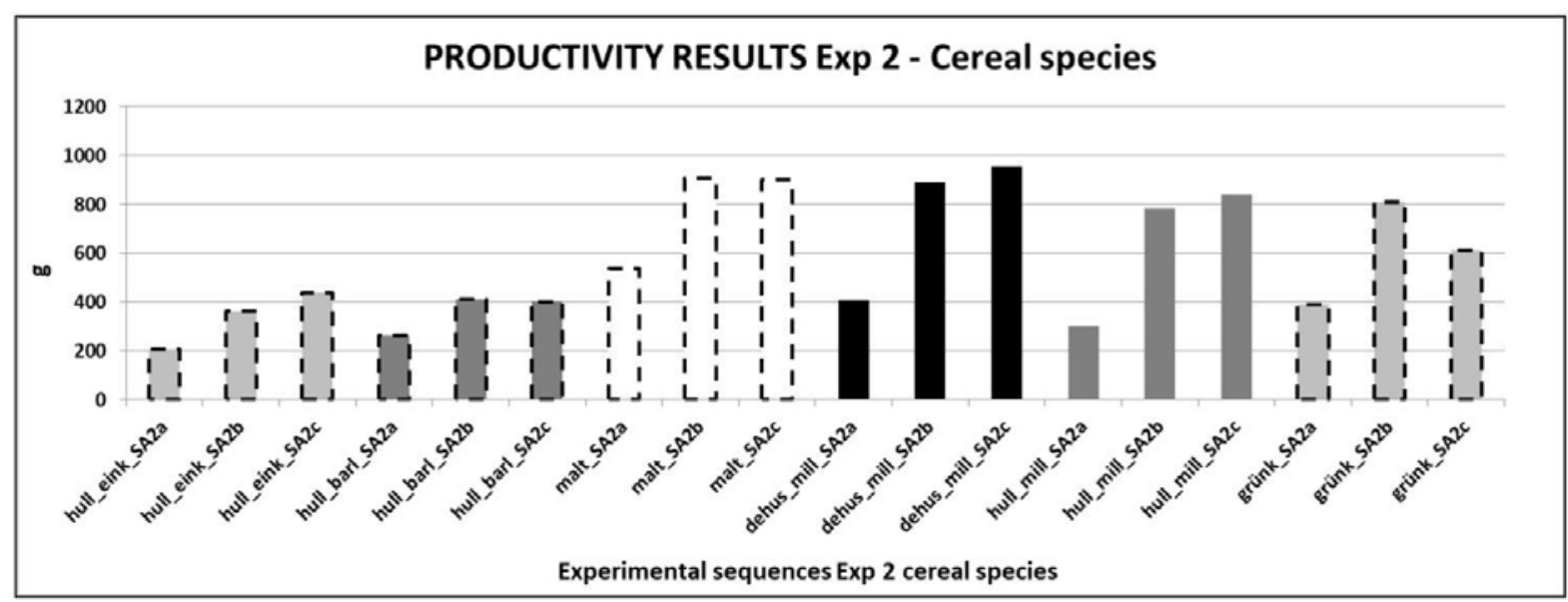

Figure 7. Results of Experiment 2 - cereal ingredients: hulled einkorn (T. monococcum), hulled barley ( $H$. vulgare), malt (toasted hulled H. vulgare), dehusked millet (P. miliaceum), hulled millet ( $P$. miliaceum), Grünkern (unripe and smoked $T$. spelta). Note: All sequences performed with SA2 tool type (sandstone tool type 2). Times in all experimental sequences are stable: $a=60 \mathrm{~min} ; \mathrm{b}=120 \mathrm{~min} ; \mathrm{c}=120 \mathrm{~min}$
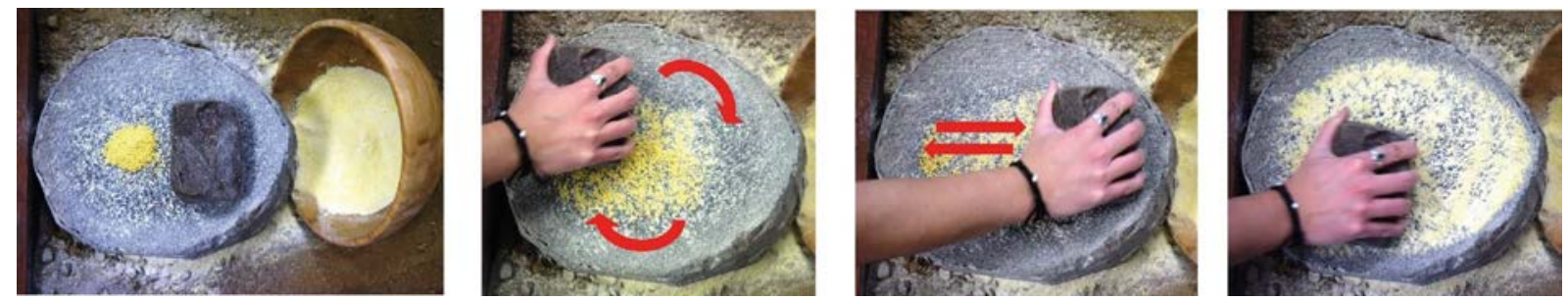

Figure 8. Experimental sequences. Experiment 2 grinding of millet with andesite type A3.

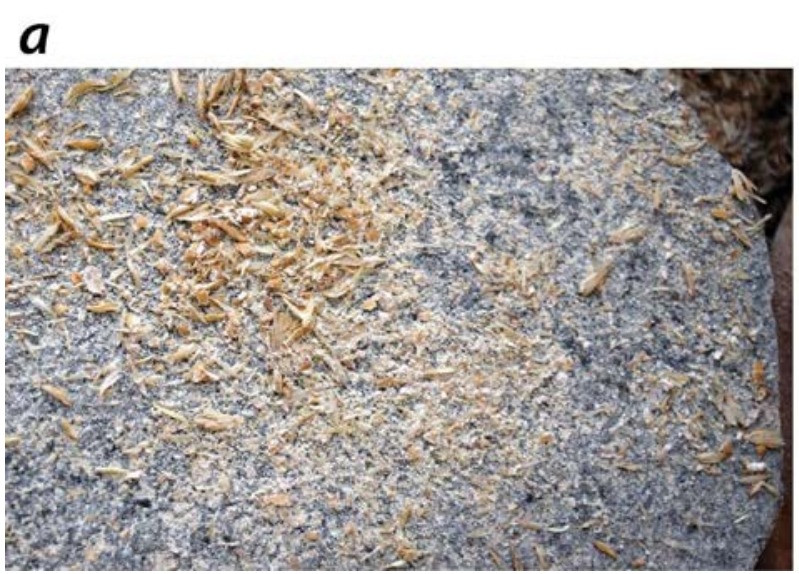

$b$

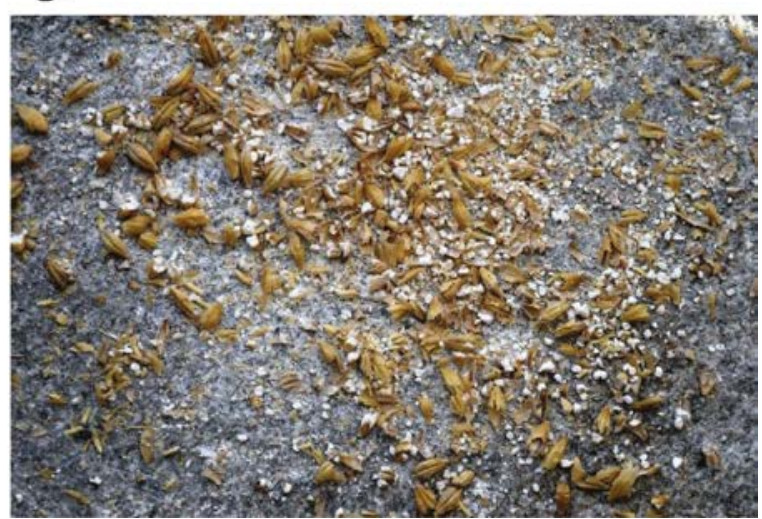

Figure 9. Experimental sequences. Fine (a) and coarse (b) grinding. 


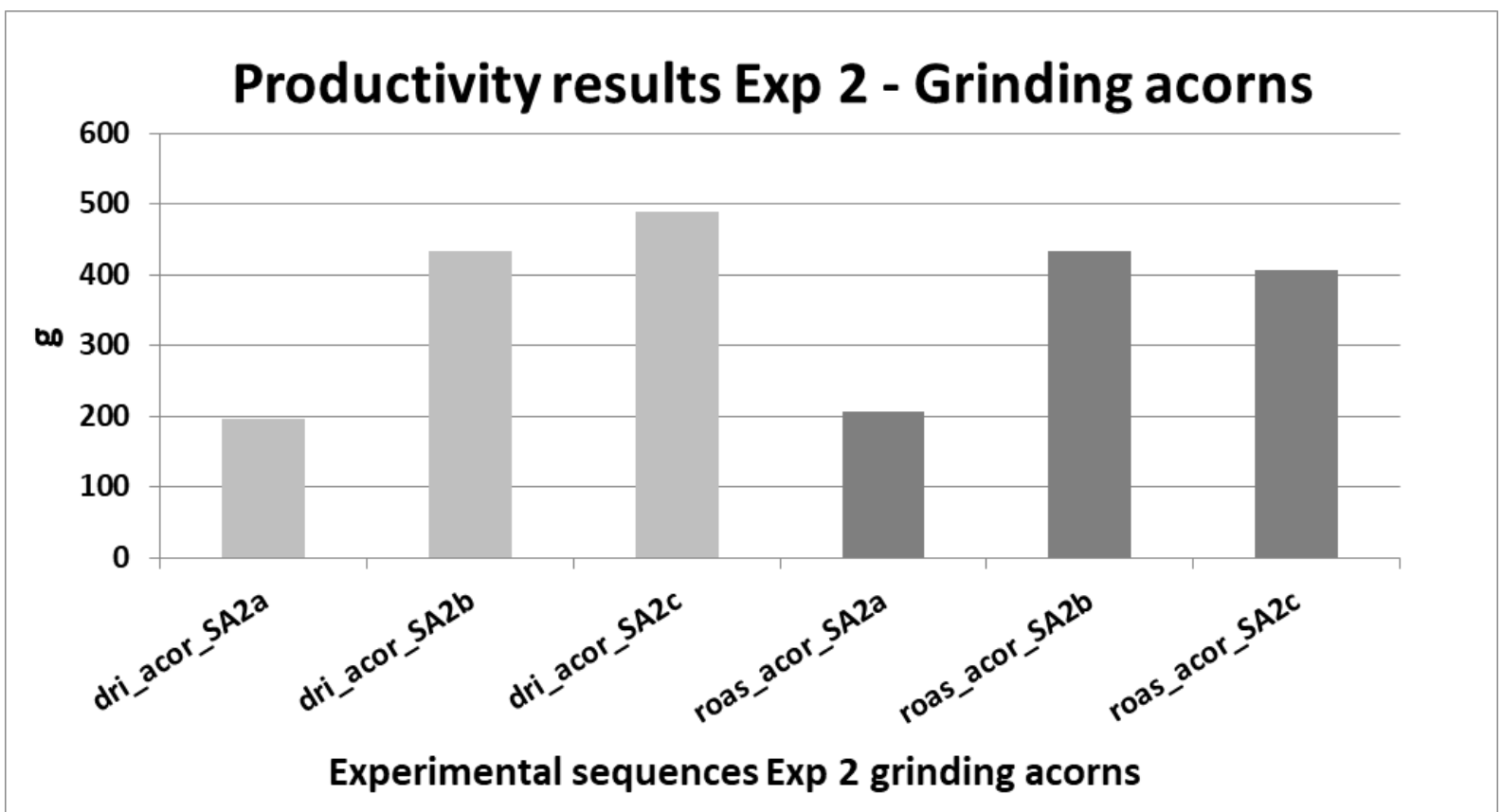

Figure 10. Results of Experiment 2 - grinding dried and roasted acorns. Note: All sequences performed with SA2 tool type. Times in all experimental sequences are stable: $a=60 \mathrm{~min} ; \mathrm{b}=120 \mathrm{~min}$; $=120 \mathrm{~min}$.

- Grinding of oily seeds. The main goal of these experiments was to crush the grains in order to extract the oil components at a later stage. According to ethnographic reports (Ertuğ 2000; Kislev et al. 2011) a usual process concerning oil-extraction from linseed involves: 1) roasting of the seeds, 2) crushing them in a mortar or grinding them with the use of grinding tools and 3) boiling with water in order to separate the oil or preparing a dough by mixing the ground material with water. This was placed afterwards on mats or in sacks or baskets, where pressure was applied (e.g., with huge stone blocks). Linseeds are small and flat grains that had to be spread out prior to grinding, and the same procedure was applied to the tiny grains of poppy seed. When the grains were successfully ground into a type of paste (Figures 11a-b), a layer of oily seed remained trapped or was sticking to the surface. The use of a brush and a hard spatula was required in order to take out the remaining paste from the active surfaces to be able to continue the grinding process (Figures 11c-d). The user noticed that the grinding of roasted poppy seeds was probably the most difficult oil seed processing sequence in terms of time and effort. On the contrary, as a general remark, the roasting pre-treatment lightly facilitates the grinding process, as can be seen in the productivity results of both species after a roasting pre-treatment (linseed: 0,588 kg per 120 min; poppy seeds: 0,775 kg per $120 \mathrm{~min}$; Figure 12).
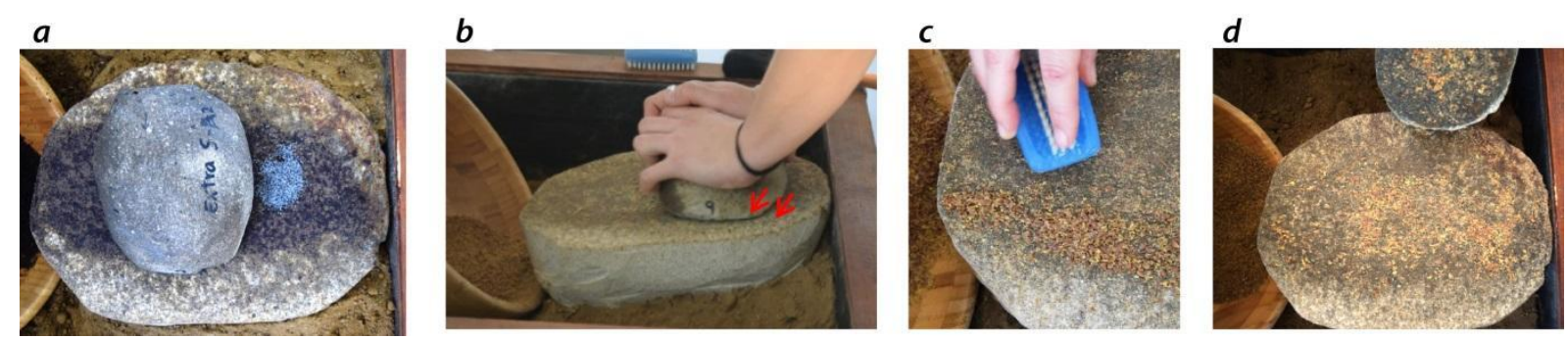

Figure 11. Experimental sequences. Experiment 2 grinding of poppy seed (a) and linseed (b). Note the sticky paste added to the surface during the oil seed processing (c-d). 


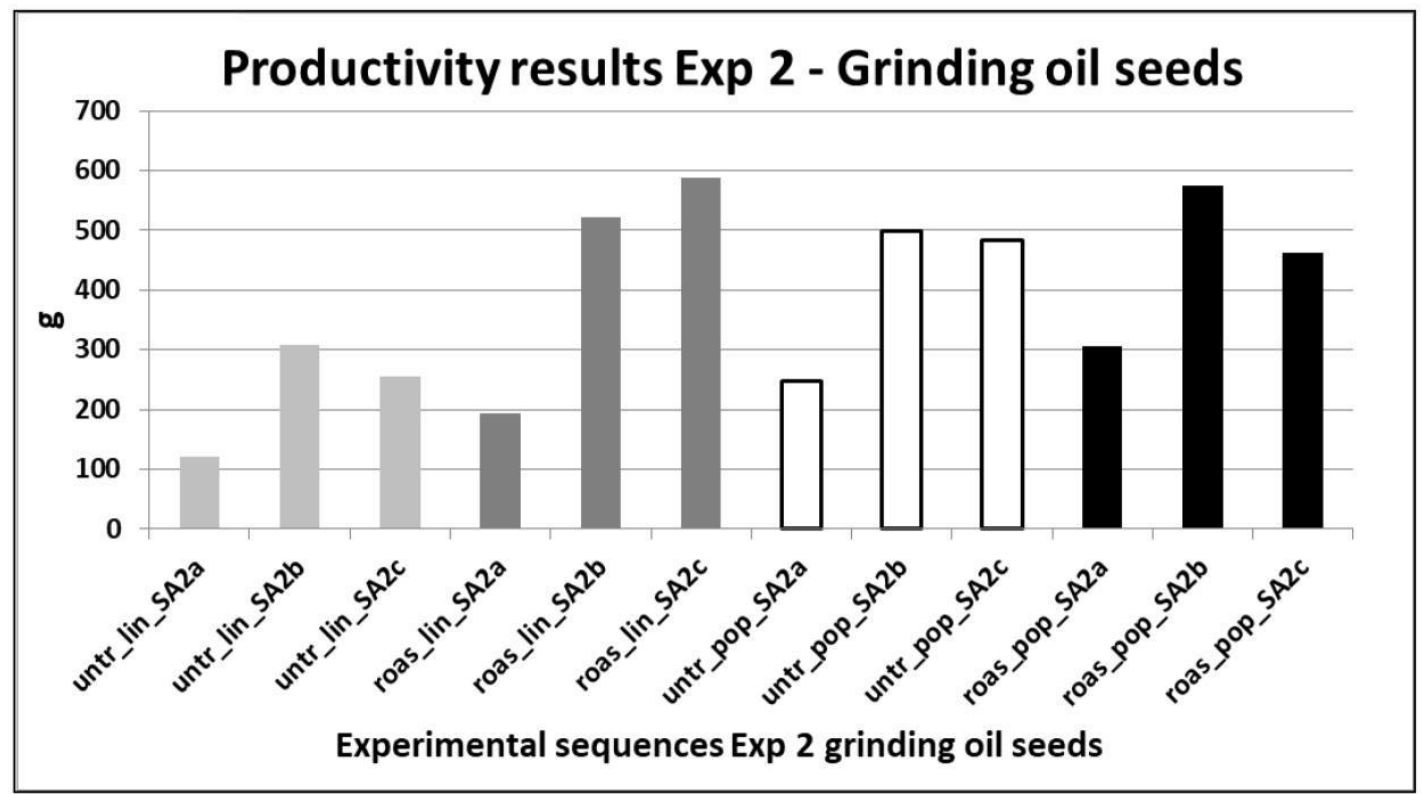

Figure 12. Results of Experiment 2 - grinding untreated and roasted linseed (Linum usitatissimum) and poppy seed (Papaver somniferum). Note: All sequences performed with SA2 tool type. Times in all experimental sequences are stable: $a=60 \mathrm{~min} ; \mathrm{b}=120 \mathrm{~min} ; \mathrm{c}=120 \mathrm{~min}$. The lower results in c sequences were probably due to the user's tiredness.

- Legume splitting. Prior to grinding pulse cotyledons (the element that has to be ground into flour), lentils and bitter vetch had been split in order to separate the testa from the cotyledon. This sequence was accomplished by using a stone quern and a handstone performing low friction movements to avoid fractures on the cotyledons. After the splitting, winnowing and sieving steps completed the cleaning process necessary before the grinding sequence. Bitter vetch was more difficult to split and grind into flour than lentils because of the round morphology of the grains (Figure 13). They fell down from the sides of the A2 quern more often than during the grinding of lentils. As mentioned below, some extra sequences revealed that type 3 artefacts are more efficient than type 2 in many cases, also for splitting round grains such as bitter vetch.

\subsubsection{Experiment 3: Long grinding sequences}

The third experiment was planned to reproduce long sequences of grinding of three main ingredients for $10 \mathrm{~h}$ in order to assess how time affects use-wear development and starch/phytolith deposition. For this experiment one of each of the raw material (sandstone, andesite and granite) and the tool types (type 1, 2 and 3) were selected in order to have a representation of long grinding sequences for both variables. Both parts of the analysis (surface characterization and residue analysis) are currently under study and will be presented elsewhere.

\subsubsection{Experiment 4: Multi-task tool processing for $\mathbf{4}$ species}

Finally, the fourth experiment was focused on the cumulative microbotanical remains and the use-wear patterns generated on tool type SA2 after the processing of different products for $8 \mathrm{~h}$, without cleaning the surface and without repecking them. This allowed exploring multifunctional culinary grinding tools, which are very common in archaeological and ethnographic cases. Both parts of the analysis (surface characterization and residue analysis) are currently under study and will be presented elsewhere. 

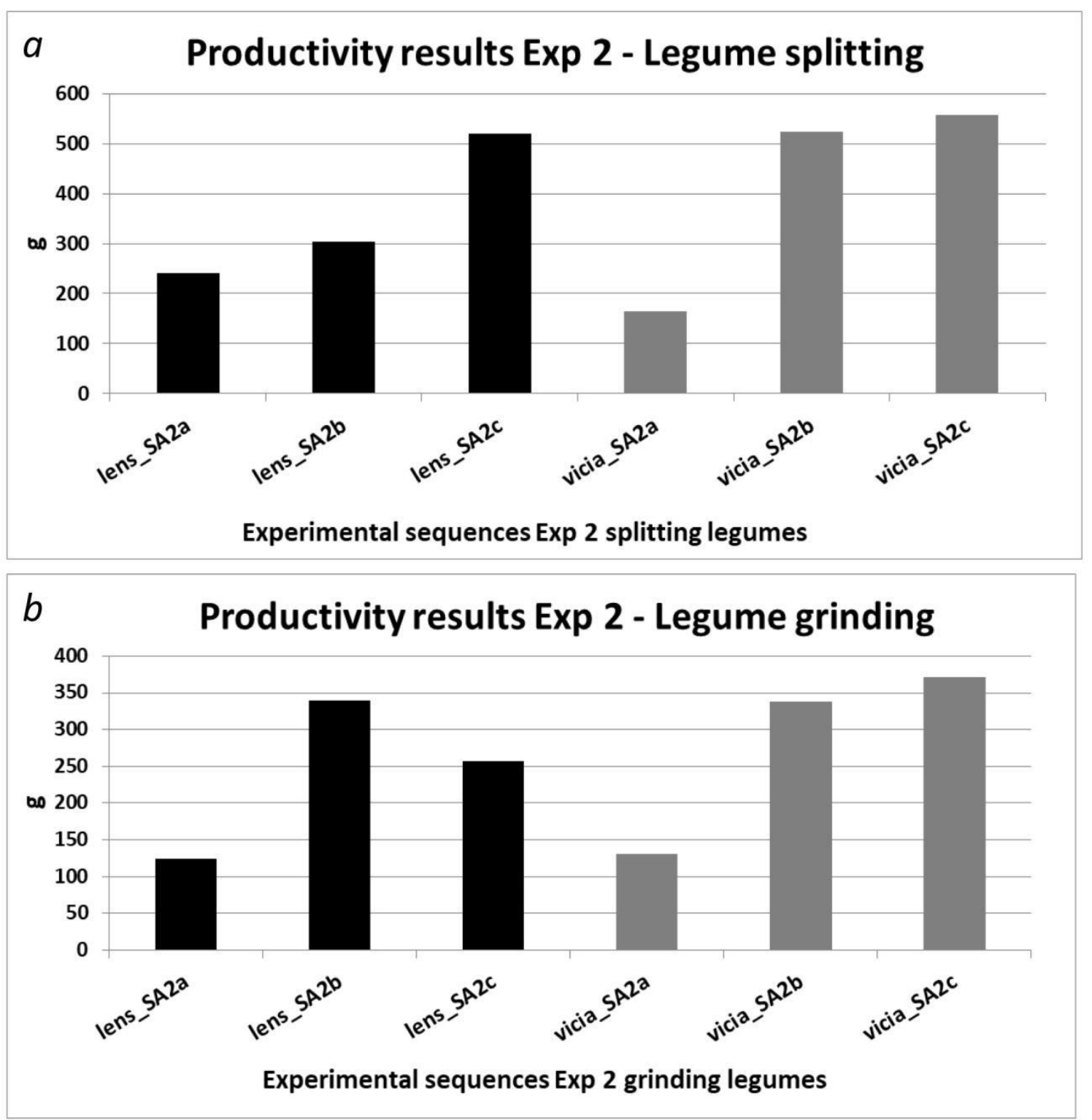

Figure 13. Results of experiment 2 - splitting (a) and grinding (b) legumes (Lens culinaris, Vicia ervilia). Note: All sequences performed with SA2 tool type. Times in all experimental sequences are stable: $a=60$ min; $b=120$ $\min$; c =120 min. The lower results in lens_SA2c were probably due to the user's tiredness.

\subsection{Use-wear results}

The PlantCult grinding experiments aim to explore the evolution and variability of usewear patterns associated with different raw materials, tool types, kinetics and plant ingredients. Main results through the analysis at macroscopic and low power magnifications are presented in table 4. 
Table 4. Use-wear results of experimental grinding tools (macroscopic and low power analyses).

\begin{tabular}{|c|c|}
\hline Experiment \& Images & Use-wear description \\
\hline x12.5 & $\begin{array}{l}\text { Distribution of use-wear: Major platforms in the centre, } \\
\text { where the previous pecked traces have been worn out by } \\
\text { the grinding (stone against stone abrasion). These } \\
\text { platforms are altered by pecked areas less affected by the } \\
\text { grinding, especially on the lateral sides of the active } \\
\text { surfaces. Only some grain levelling on low topography. } \\
\text { Morphology of topography: Flat and sinuous platforms on } \\
\text { tool types } 1 \text { \& 2, more rounded morphology on tool type } \\
3 . \\
\text { Use-wear traces: Grain removal and rounding on the } \\
\text { more exposed zones (high topography). Low macroscopic } \\
\text { polish on the central area. Striations on bigger inclusions. }\end{array}$ \\
\hline $\begin{array}{lll} & \\
\text { E2.1b_qSA2 } & \times 10\end{array}$ & $\begin{array}{l}\text { Distribution of use-wear: The initial pecked surfaces } \\
\text { (manufacture) are quite preserved after the grinding. } \\
\text { Only presence of some rough levelling in areas where } \\
\text { handstone and quern contact was more intense (central } \\
\text { area). The low topography persisted almost unaltered. } \\
\text { Morphology of topography: Sinuous platforms and } \\
\text { angular edges of grains. } \\
\text { Use-wear traces: Low grain rounding. Low polish on } \\
\text { individual grains summit (due to the silica husks } \\
\text { processing effect). Microfractures preserved form the } \\
\text { manufacture sequence. Absence of linear traces. }\end{array}$ \\
\hline E2.4b_qSA2 & $\begin{array}{l}\text { Distribution of use-wear: Extended platforms affected by } \\
\text { a dark discoloration appeared in the central area. The } \\
\text { abrasion also generated a rough surface in the centre. } \\
\text { Morphology of topography: Rounded morphology of } \\
\text { platforms with tool type 3. Grain rounding in low } \\
\text { topography and intermediate zones. } \\
\text { Use-wear traces: Dark discoloration on macroscopic view } \\
\text { that is seen as polish under more magnifications. Grain } \\
\text { borders are much diffused, covered by the polish. Linear } \\
\text { traces in the form of alignments of pecking pits, and short } \\
\text { small striations over the bigger crystals. }\end{array}$ \\
\hline 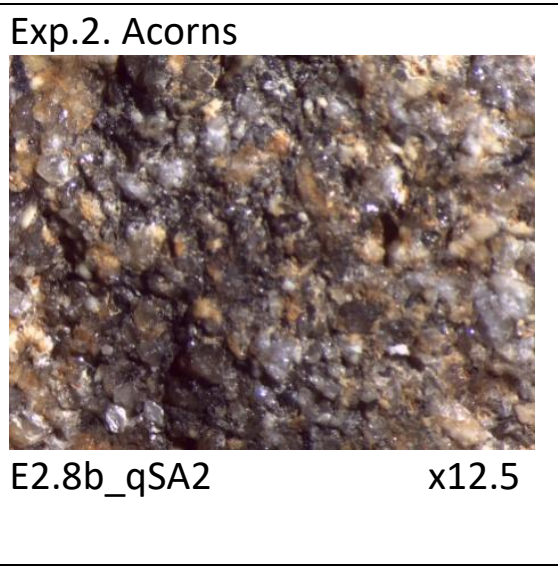 & $\begin{array}{l}\text { Distribution of use-wear: The processing of roasted } \\
\text { acorns caused more intense use-wear patterns than the } \\
\text { dried acorns, such as more extended smooth areas, and } \\
\text { darker and matte discoloration. The pounding strokes to } \\
\text { crush the fruits maintained the pecked rough area in the } \\
\text { centre of the active surface. } \\
\text { Morphology of topography: Angular edges of platforms. } \\
\text { No damage on low topography. } \\
\text { Use-wear traces: Some striations in the proximal end } \\
\text { produced by grain removal and microfractures. Grain } \\
\text { rounding, but not total levelling of platforms. Low polish }\end{array}$ \\
\hline
\end{tabular}




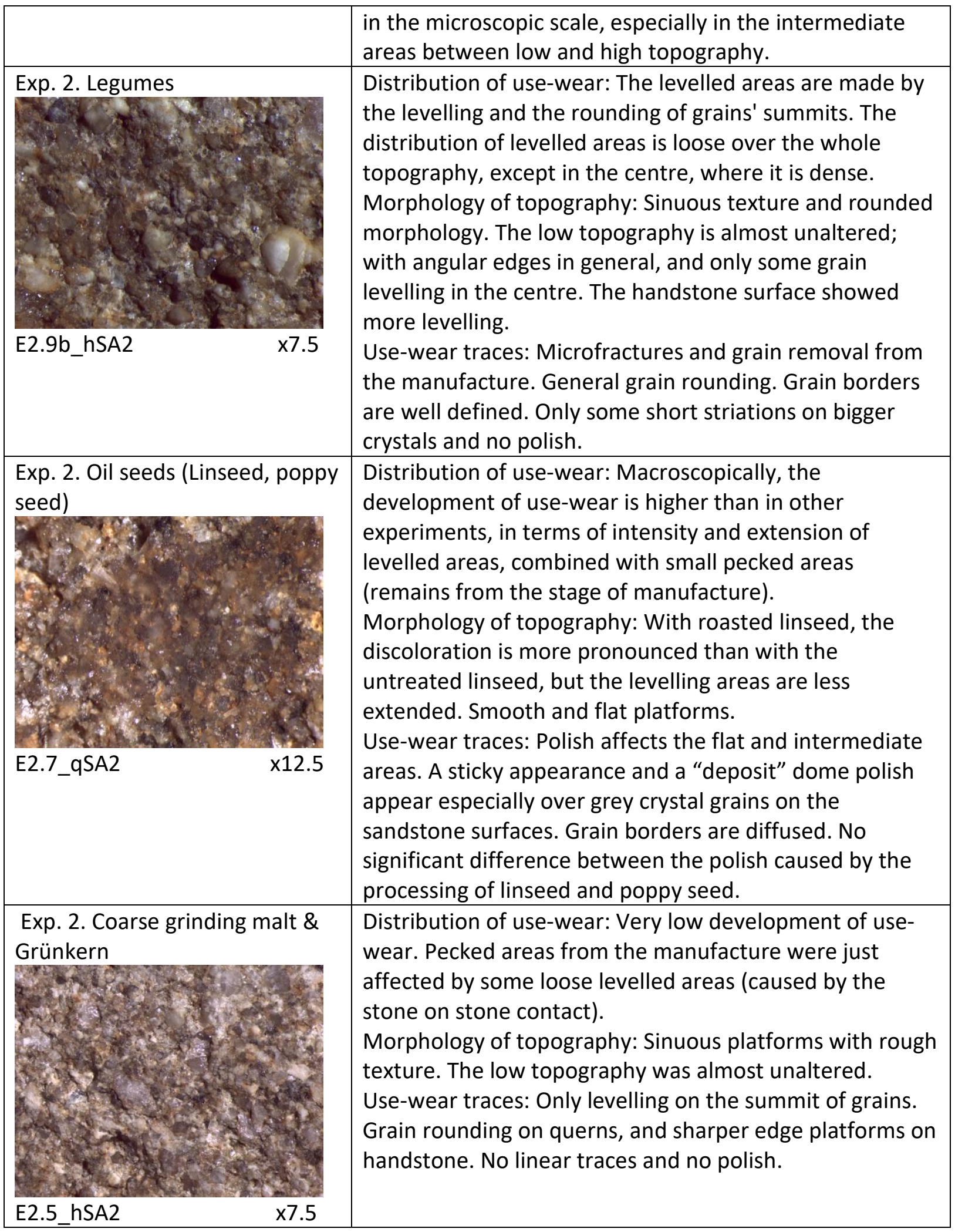

\section{Discussion}

Concerning tool size, the new PlantCult data showed that tool dimensions have an evident effect on the quantity of product obtained (see examples of other results in Mildwaters \& Clarkson 2018), but it also revealed the good productivity of the so-called "small tools" (the average is $1,5 \mathrm{~kg}$ of ground product in $5 \mathrm{~h}$ ). In that sense, as experimental (Procopiou 
1998; Valamoti et al. 2013) and ethnographic (i.e., Gast 1968) data proposed, small grinding toolkits are suitable in means of obtaining cereal flour (against Runnels 1981 theory). Furthermore, distribution patterns of the archaeological tools within settlement can reflect different efficient production strategies (communal or household) which mobilise big tools along with small ones.

The role of apprenticeship in technology is widely discussed in other scientific areas as anthropology, sociology, psychology and cognitive sciences. Whittaker (2004) focused on actual flint knappers to observe experimental apprenticeship, but this approach is rarely applied in experimental programs. In that sense, the productivity tests of controlled experiments performed in Experiment 1 had minimized such variability in the quantitative results.

One of the main axes of analysis of Experiment 2 was to evaluate the grinding process associated with hulled and dehusked cereals. The difference in $\mathrm{kg}$ per $\mathrm{h}$ is quite significant between hulled and dehusked. Despite a sieving sequence would be needed after the grinding of hulled grains, ethnographic, historical and archaeological references talk about the taste of non-totally dehusked cereals, obtaining in that way a wide range of textures, flavors and nutritional qualities highly appreciated in some contexts (see references in Procopiou 2003).

About the high output of the millet grinding sequences - especially in dehusked state and processed with type 3 toolkit - factors such as the small size, the round morphology and the softness of millet grains could explain these results. Mildwaters and Clarkson (2018) achieved similar results comparing different seed processing among which millet varieties had a high productivity. Concerning our results, the smaller and lighter handstone AA3 permits a greater movement over the active surface of the quern and so increases the velocity of the grinding.

Coarse grinding achieved good results in terms of the quality of the ground product and its productivity. Concerning coarse grinding and other treatments that need the use of sieves, textual evidence in the Near East during the 3rd millennium BCE (Gregoire 1992) attest to the existence of various sieves: the sieve for gruel, the sieve for linen, the sieve for barley flour, the sieve for fine flour, etc.

Legumes, acorns and oil seeds were satisfactorily ground by using the SA2 toolkit, one of the most common sets of grinding tools in the archaeological record. All the plant ingredients required some initial pounding strokes to open the grain (vertical percussion), and then the user was able to start grinding. This first stage was especially relevant in some experiments such as acorns, oil seeds, grass pea and bitter vetch. As the pounding movement implies lifting of the handstone, probably big and heavy handstone types such as B1 and B2 (6-7 kg) are not suitable for processing these plant ingredients. To raise heavy tools for long processing sequences as in Experiments 3 and 4 can be a hard operation, becoming more comfortable with the use of lighter handstones.

A similar situation was detected with A3 and B3 handstone types that are characterized by active surfaces with a convex morphology in both sections. In handstones, the convex morphology is not suitable for vertical percussion movements (e.g., pounding to open the testa of legumes), since the strokes provoke the sliding out of the grain from the querns surface. However, the concave morphology of type 3 querns permits the retainance of the grain. Finally, A3 and B3 handstones (used in a circular movement) worked much better to split rounded grain legumes than the linear back and forth A2 used in Experiment 2.

The identification of use-wear patterns on the grinding tools is an essential step to explore the introduction of new plant species and the subsequent changes in grinding techniques in the studied areas. In relation to the rhythm of use-wear formation in the experiments, a group of sequences left scarce surface alteration even after $5 \mathrm{~h}$. Thus for exemple, the use wear traces appear more slowly during legumes processing, coarse grinding, 
and the use of granite tools (a harder raw material) than for other substances and tools. This issue must be taken into account during comparison with worn archaeological surfaces.

The raw material properties of the stone tools have clear effects on the evolution of the wear and on the characteristics of the obtained product (fineness, stone-particle contamination, etc., that will be treated in further studies). During use, the roughness is decreased significantly for sandstone and for some andesite blocks, and the necessity to renew the roughness of the surface (repecking) is increased.

About the role of kinetics in the use-wear development, we noticed that vertical percussion (pounding) generated microfractures, grain removal and striations. The orientation of the grinding movements also influences wear patterns. The pendulum movement of the handstone in tool type 3 (circular strokes) tends to create more rounded plateaus on surfaces than types 1 and 2 (back and forth motion), in which the rectilinear movements generate flatter plateaus with more angular edges.

Smaller grains (i.e., millet) caused more friction between handstone and quern surfaces, which means a higher degree of wear. A similar wear process was observed for fine or coarse grinding, that also implied a difference in the force used by the grinder (more strength in fine grinding $=$ more friction $=$ more use wear). As a consequence, the processing of malt and Grünkern has a low visibility in terms of use-wear traces. However, the technical requirements to process these ingredients (light vertical strokes and a few grinding strokes) suggest that the same grinding implements used for fine grinding can be used for coarse grinding.

It was expected that the processing of oil seeds and acorns would generate oil residues and dark stains due to their chemical composition. However, millet caused a brighter surface than the other plant ingredients. Even after alcohol cleaning, these use-wear patterns persisted. Roasting grains also increased the intensity of use-wear compared to dried grains (due to the chemical transformation of grains after the roasting).

Moreover, millet processing left more extended plateaus of homogenous microtopography with a darker discoloration of the surface and wider polished areas than the ones observed after einkorn and barley grinding (see images in Table 4). These use-wear patterns were very striking, even macroscopically. In order to obtain signatures of wear for each material processed in the experiments, a new study is in progress at the Laboratorie de Tribologie et Dynamique des Systèmes (Ècole Centrale de Lyon). The analysis includes the use of specific parameters of surface characterization as a method of continuous wavelet transforms (Bofill et al. 2013; Vargiolu 2008). This characterization will also be applied to archaeological tools to detect the processing of different plant ingredients and to analyse the processing techniques associated in each archaeological case study.

\section{Conclusions}

First of all, the productivity test of grinding sequences has underlined the importance of apprenticeship in experimental studies, especially when results are treated from a quantitative point of view. Secondly, the controlled experimental sequences established that the concave querns (tool type 3) operated in circular motion reached the highest quantity of ground product compared with querns with back and forth motion (types 1 and 2). These results were obtained with both size categories. The only exception was of granite type 2 which achieved high results, and which also demonstrated the highest productivity of this raw material among the others stone types (sandstone and andesite).

In terms of size and productivity, the wider active surfaces of "big" tools produced a considerably high quantity of ground product (einkorn cereal) compared with the "small" toolkit results. Despite this general trend, the so-called "small" tools also achieved great 
quantities of ground product (particularly tool type 3). In addition, questions as to the organization of grinding activities, plant ingredients and recipes to be obtained, and the scale of production (domestic, communal, etc.) must be included in the study in order to examine the role of small toolkits in prehistoric sites.

Experiment 2 confirmed the viability of using one of the most conventional grinding toolkits documented in the archaeological archive (tool type 2 made of sandstone) in the processing of a variety of plant-ingredients (cereals, legumes, acorns and oil-seeds). These results could support hypotheses about the existence of multifunctional grinding toolkits, which can coexist with more specialized tools. The stereomicroscope analysis of surfaces suggested that longer grinding sequences of some of the plants processed in the experiments are required in order to obtain clear use-wear signatures (i.e., legumes, coarse grinding of cereals).

The next steps in the project will connect the experimental data with the archaeological database, the analysis of plant micro-remains, and will also explore the blended use of querns with other tools types, such as mortars and pestles (made of wood and or stone) in the preparation of food recipes. All these experimental data will definitely have important implications for the interpretation of grinding stone tools in the context of transformation of culinary practices in ancient societies.

\section{Acknowledgements}

This work has been funded by the European Research Council project "PLANTCULT: Identifying the food cultures of ancient Europe”, under the European Union Horizon 2020 research and innovation program (Grant Agreement No 682529, Consolidator Grant 20162021. We would like to thank the team grinders Eleftheria Almasidou and Pavlos Lathiras. The microbotanical team Sofia Laparidou, Calla McNamee and Georgia Tsarsidou. Members of the Geology Dept. (AUTH) participating in the expeditions, Dr. Lambrini Papadopoulou, Aris Stamatiadis, Nikos Kardakos, Thomas Dimitroudis, Giannis Galanis, Eleni Michailidou, Eutychia Petika and Anna Bourliva. Prof. Vergopoulos and the technician Mr. Dinos Pavlides (3D analysis, Dep. of Architecture AUTH).We would also like to thank the suppliers of plant ingredients used in the experiments: grass pea from Agrino Company (Greece), the malt from Vergina Beer (Greece), the acorns from Kosmati, Greneva (Greece, special thanks to Ioanna Mimi and her family), the Grünkern from Germany (special thanks to Hans-Peter Stika and Marian Berihuete-Azorin), and the millet from Lithuania (special thanks to Giedre Motuzaite Matuzeviciute).

\section{References}

Adams, J. 2002. Ground stone analysis. A technological approach. The University of Utah Press, Salt Lake City: 310 p.

Adams J. 2010, Understanding Grinding Technology through Experimentation, In: Designing Experimental Research in Archaeology: Examining Technology through Production and Use, (Ferguson J., Ed.), University Press of Colorado, Louisville: p. 129-152

Adams, J., Delgado, S., Dubreuil, L., Hamon, C., Plisson, H., Risch, R. \& Eigeland, L. 2009. Functional Analysis of macro-lithic artefacts: a focus on working surfaces. In: NonFlint Raw Material Use in Prehistory. Old prejudices and new directions.Proceedings of the XV World Congress UISPP (Lisbon, 4-9 September) (Sternke, F., Eigeland, L., \& Costa, L.-J., Eds.), BAR International Series Vol. 1939, Archaeopress, Oxford: p. 4366. 
Bofill, M. 2015, Inicio y consolidación de las prácticas agrícolas durante el neolítico en el levante mediterráneo (septentrional y central): El proceso de molienda y trituración a partir del análisis funcional del instrumental macrolítico Ph. D. Thesis. Departament of Prehistory. Autonomous University of Barcelona. Barcelona,737 p. (in Spanish) ("Beginning and consolidation of agricultural practices during the Neolithic period in the Levant (north and central): The study of grinding and pounding processes from the functional analysis of the macrolithic instruments").

Bofill, M., Procopiou, H., Vargiolu, R. \& Zahouani, H. 2013. Use-wear analysis of near eastern prehistoric grinding stones. In: Regards croisés sur les outilsliés au travail des végétaux. An interdisciplinary focus on plant working tools (Anderson, P. C., Cheval, C., \& Durand, A. Eds.). APDCA, Antibes. p. 225-242.

Delgado, S. 2008. Prácticas económicas y gestión social de recursos (macro)líticos en la Prehistoria Reciente (III-I Milenio AC) del Mediterráneo Occidental, Ph.D Dissertation, Universitat Autònoma de Barcelona, Bellaterra,758 p. (in Spanish) ("Economic practices and social management of technical resources in Late Prehistory (III-I Millennium BC) of the Mediterranean Western”).

Delgado, S., Gómez-Gras, D. \& Risch, R. 2009. The mechanical properties of macrolithic artifacts: a methodological background for functional analysis, Journal of Archaeological Science, 36(9): 1823-1831. doi:10.1016/j.jas.2009.03.033

Delgado, S. \& Risch, R. 2009. Towards a systematic analysis of grain processing technologies. In: Recent functional studies on non flint stone tools: Methodological improvements and archaeological inferences, 23-25 May 2008, Lisboa. (de Araújo M. \& Clemente I. Eds.). Lisboa. [CDROM] p. 1-20.

Driver, H. E. 1952. The acorn in North American Indian diet. Proceedings of the Indiana Academy of Science. 62: 56-62.

Dubreuil, L. 2002, Etude fonctionnelle des outils de broyage natoufiens: nouvelles perspectives sur l'émergence de l'agriculture au Proche-Orient, Ph.D thesis, Bordeaux I University, Bordeaux. 586 p. (in French) ("Functional study of the Natufian grinding tools: new perspectives on the emergence of agriculture in the Middle East").

Dubreuil, L., Savage, D., Delgado-Raack, S., Plisson, H., Stephenson B. \& de la Torre, I. 2015, Current Analytical Frameworks for Studies of Use-Wear on Ground Stone Tools. In: Use-Wear and Residue Analysis in Archaeology, Manuals in Archaeological Method, Theory and Technique (Marreiros, J. M., Gibaja B. J. F. \& Ferreira Bicho, N., Eds.)., Springer International Publishing, Amsterdam: p.105-158. doi:10.1007/978-3319-08257-8_7

Ertuğ, F. 2000. Linseed oil and oil mills in central Turkey. Flax/Linum and Eruca, important oil plants of Anatolia. Anatolian Studies. 50: 171-185. doi:10.2307/3643022

Foxhall, L. 1982, Experiments in the processing of wheat and barley. In: Sitometria: the role of grain as a staple food in classical Antiquity (Foxhall L. \& Forbes H., Eds.), Chiron. Mitteilungen der Kommission für Alte Geschichte und Epigraphik des Deutschen Archäologischen Instituts 12: p. 41-90, Appendix.p. 75-81.

Gast, M. 1968. Alimentation des populations de l'Ahaggar: étude ethnographique. Arts et métiers graphiques, Paris, 457 p. (in French) ("Food of the Ahaggar populations: ethnographic study”). 
Geslin, P, 1999. L'Apprentissage des mondes. Une anthropologie appliquée aux transferts de technologies, Octares/MSH, Paris, 254 p. (in French) ("Learning the worlds. An anthropology applied to technology transfer")

Gregoire J.-P. 1992. Les grandes unités de transformation des céréales: l'exemple des minoteries de la Mésopotamie du Sud à la fin du IIIe millénaire avant notre ère. In: Préhistoire de l'agriculture. Nouvelles approches expérimentales et ethnographiques (Anderson P.C., Ed.), CNRS Editions, Paris: p. 321-339. (in French) ("Large cereal processing units: the example of mills in southern Mesopotamia at the end of the third millennium BC”).

Hamon, C. 2006. Broyage et abrasion au Néolithique ancien. Caractérisation technique et fonctionnelle des outillages en grès du Bassin parisien. BAR International Reports S1551, Archaeopress, Oxford, 342 p. (in French) ("Grinding and abrasion in the ancient Neolithic. Technical and functional characterization of sandstone tools in the Paris Basin”)

Heiss, A.G., Antolín, F., Bleicher, N., Harb, C., Jacomet S \&Kühn, M. 2017. State of the (t)art. Analytical approaches in the investigation of components and production traits of archaeological bread-like objects, applied to two finds from the Neolithic lakeshore settlement Parkhaus Opéra (Zürich, Switzerland). PLoS ONE, 12(8): e0182401. doi:10.1371/journal.pone.0182401

Horsfall, G. A. 1987. Design Theory and Grinding Stones. In: Lithic Studies among the Contemporary Highland Maya, (Hayden, B., Ed.), University of Arizona Press, Tucson: p. 332-337

Kislev, M.E., Simchoni, O. Melamet, Y. \&Maroz, L. 2011. Flax seed production: Evidence from the early Iron Age site of Tel Beth Shean, Israel and from written sources. Vegetation History and Archaeobotany, 20(6): 579-584. doi:10.1007/s00334-011-03035

Liu, L., Field, J., Fullagar, R., Bestel, S., Chen, X. \& Ma, X. 2010, What did grinding stones grind? New light on early Neolithic subsistence economy in the Middle Yellow River Valley, China. Antiquity: a quarterly review of archaeology, 84 (325): 816-833.

Marinova, E. \& Valamoti, S.M. 2014. Crop diversity and choice in prehistoric South-eastern Europe: cultural and environmental factors shaping the archaeobotanical record of northern Greece and Bulgaria. In: Plants and people: choices and diversity through time (Marinova, E., Heiss, A. Eds.), Oxbow, Oxford: p. 46-54 and 92-102.

Mason, S. \& Nesbitt. M. 2009. Acorns as food in southeast Turkey: implications for prehistoric subsistence in Southwest Asia. In: From foragers to farmers: papers in honour of Gordon C. Hillman (Fairbairn, A., \& Weiss, E. Eds). Oxbow Books, Oxford: p.71-85.

Mauss, M. 1950. Sociologie et anthropologie. Les Presses universitaires de France, Paris: 482 p. (in French) ("Sociology and anthropology”).

Menasanch M., Risch R. \& Soldevilla J. A. 2002. Las tecnologias del procesado de cereal en el sudeste de la peninsula Ibérica durante el III y el II milenio A.N.E. In: Moudre et Broyer: l'interprétation fonctionnelle de l'outillage de mouture et de broyage dans la Préhistoire et l'Antiquité (Procopiou, H. \&Treuil, R. Eds). CTHS, Paris: p. 81-110. (in French) ("The technologies of cereal processing in the southeast of the Iberian Peninsula during the III and II millennium BC”). 
Meurers-Balke, J., \& Lüning, J. 1992. Some aspects and experiments concerning the processing of the glume wheat. In: Préhistoire de l'Agriculture, Nouvelles Approches Expérimentales et Ethnographiques (Anderson, P. C., Ed.), Monographie du CRA 6, Paris: p. 341-362.

Mildwaters, J. \& Clarkson, C. 2017. The efficiency of Australian grindstones for processing seed: A quantitative experiment using reproduction implements and controlling for morphometric variation and grinding techniques. Journal of Archaeological Science: Reports, 17: 7-18. doi:10.1016/j.jasrep.2017.10.036

Procopiou, H. 1998. L'outillage de mouture et de broyage en Crète Minoenne. Ph. D. Thesis. Université de Paris I. Panthéon-Sorbonne. 231 pages. (in French) ("Grinding and grinding tools in Minoan Crete”).

Procopiou, H. 2003. Les techniques de décorticage dans le monde égéen. Étude ethnoarchéologique dans les Cyclades. In: Le traitement des récoltes: un regard sur la diversité, du Néolithique au Present. III rencontres internationales d'archéologie et d'histoire d'Antibes (Anderson, P.C., Cummings, L. S., Schippers, T. K. \&Simonel, B., Eds.), APDCA, Antibes: p. 115-136. (in French) ("Dehusking techniques in the Aegean world. Ethnoarchaeological study in the Cyclades").

Procopiou, H., Jautée, E., Vargiolu, R. \& Zahouani, H. 1998. Petrographic and use-wear analysis of a quern from Syvritos Kephala. In: Functional analysis of lithic artefacts: current state of the research. Proceedings of the XIII UISPP Congress (Forli, 8 - 14 september1996) (Facchini, F., Palma di Cesnola, A., Piperno, M. \& Peretto, C. Eds.). Forli, ABACO Edizioni. p. 1183-1192.

Runnels C., 1981. A Diachronic Study and Economic Analysis of Millstones from the Argolid. Ph.D. Dissertation. Indiana University, Bloomington, 402 p.

Sigaut, F. 2003, La formule de Mauss, Techniques et Culture, 40: 153-168. doi:10.4000/tc.1538. (in French) ("Mauss's formula”).

Schneider, J. 2002. Milling tool design, stone textures and function. In: Moudre et Broyer: l'interprétation fonctionnelle de l'outillage de mouture et de broyage dans la Préhistoire et l'Antiquité (Procopiou, H. \&Treuil, R. Eds), CTHS, Paris: p. 31-53.

Schoumacker, A. 1993. Apports de de la technologie et de la pétrographie pour la caractérisation des meules. In: Traces et fonction: les gestes retrouvés. Colloque international de Liège, 8-9-10 décembre 1990 (Anderson, P. C., Beyries, S., Otte, M., \& Plisson, H.), Service de Préhistoire, Université de Liège. Liège: p. 165-176. (in French) ("Contributions of technology and petrography for the characterization of grinding implements”).

Stika, H.-P. \& Heiss, A.G. 2013. Plant cultivation in the Bronze Age. In: The Oxford Handbook of the European Bronze Age (Fokkens, H. \& Harding, A., Eds.), Oxford University Press, Oxford: p. 348-369.

Stroulia, A. 2010. Flexible stones. Groundstone tools from Franchthi Cave. Fascicle 14, Excavations at Franchthi Cave, Greece. Bloomington, Indiana University Press, Indianapolis, 242 p. doi:10.2307/j.ctv80cdgp

Stroulia, A., Dubreuil, L., Robitaille, J. \& Nelson, K. 2017, Salt, Sand, and Saddles: Exploring an Intriguing Work Face Configuration among Grinding Tools, Ethnoarchaeology, 9(2): 119-145. doi:10.1080/19442890.2017.1364053 
Tsoraki, C., 2007. Unravelling Ground Stone Life Histories: the Spatial Organization of Stone Tools and Human Activities at LN Makriyalos, Greece. Documenta Praehistorica, 34: 289-298. doi:10.4312/dp.34.22

Valamoti, S.M. 2007. Food across borders: a consideration of the Neolithic and Bronze Age archaeobotanical evidence from northern Greece. In: Between the Aegean and Baltic Seas: Prehistory across Borders (Galanaki, I., Tomas, I., Galanakis, Y. \& Laffineur, R., Eds.). Aegeum Vol 27: p. 281-293.

Valamoti S. M., 2009. Plant food ingredients and 'recipes' from prehistoric Greece: the archaeobotanical evidence In: Plants and Culture: Seeds of the Cultural Heritage of Europe (Morel, J. P., Mercuri, A. M., Eds.), Centro Europeo per I Beni Culturali Ravello, Edipuglia, Bari: p. 25-38.

Valamoti, S.M. 2011. Ground cereal food preparations from Greece: the prehistory and modern survival of traditional Mediterranean 'fast foods'. Archaeological and Anthropological Sciences, 3(1): 19-39. doi:10.1007/s12520-011-0058-z

Valamoti, S. M., Chondrou, D. \& L. Papadopoulou. 2013. Plant food processing and ground stone equipment in prehistoric Greece: An experimental investigation using seeds of einkorn and grass-pea. In: Regards croisés sur les outils liés au travail des végétaux : Actes des 33e rencontres internationales d'archéologie et d'histoire d'Antibes, 23-25 octobre 2012 (Anderson, P. C., Cheval, C., \& Durand, A. Eds.). APDCA, Antibes. p. 169-188.

Valamoti, S.M., Jacomet, S.Stika, H.-P., \& Heiss, A. G. 2017. The PLANTCULT Project: identifying the plant food cultures of ancient Europe. Antiquity Project Gallery,91(358): doi:10.15184/aqy.2017.130

Vargiolu, R. 2008. De la fabrication à l'utilisation d'objets archéologiques. Apport de la tribologie. Ph. D. Thesis. École Centrale de Lyon, Lyon (in French). 311 pages. ("From the manufacture to the use of archaeological objects. The contribution of tribology").

Vencl, S. 1996. Acorns as food: again. Památky archeologické, 87(2): 95-111.

Whittaker, J. 2004. American flint knappers: Stone age art in the age of computers, University of Texas Press, Austin, 353 p. 